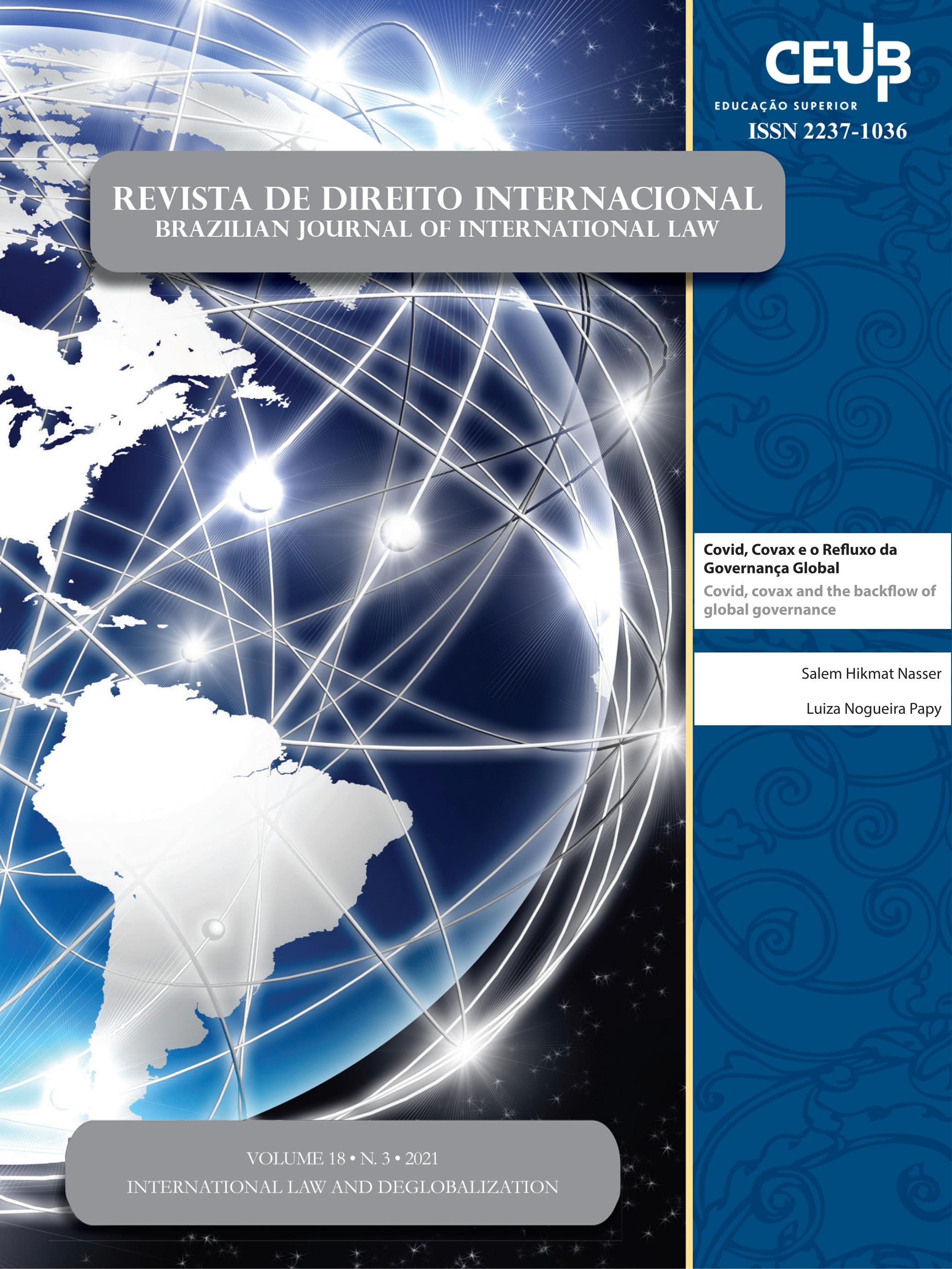




\section{Sumário}

Dossiê

EDITORIAL: INTERNATIONAL LAW AND DE-GLOBALIZATION 16 Ivette Esis, Jaime Tijmes e Juan Enrique Serrano

El régimen jurídico de la Inversión Extranjera Directa: ¿De la limitación a la desGLOBALIZACIÓN?

Ivette Esis Villarroel e Yoselyn Bermúdez Abreu

Desglobalização, Brexit e os novos acordos entre Reino Unido e União Europeia .34 Angela Limongi Alvarenga Alves e Daniel Freire e Almeida

FisCALIDAD Y DESGLOBALIZACIÓN EN UN MUNDO CRECIENTEMENTE UNILATERAL Julio César Muñiz Pérez

Covid, Covax e o Refluxo da Governança Global Salem Hikmat Nasser e Luiza Nogueira Papy

The International Monetary Fund and COVID-19: Old and New Challenges of a Post-World War II INTERNATIONAL INSTITUTION

Virdzhiniya Petrova Georgieva

Artigos Sobre outros temas

RULE OF LAW IN THE INTERNATIONAL ARENA: THE IMPORTANCE OF PRACTICES OF LEGALITY . 112 Angela Jank Calixto

THE WITHDRAWAL OF MEMBER-STATES FROM HUMAN RIGHTS COURTS: IS THE JUDICIALIZATION OF MEGA-POLITICS A NECESSARY CONDITION?. 132

Mikelli Marzzini Lucas Alves Ribeiro e Ernani Rodrigues de Carvalho Neto 
Princípio da precaução e mudança climática: uma análise do Acordo de Paris e das Conferências das Partes.

Jamille Bergamaschine Mata Diz e Carolina Mendonça de Siqueira

A INTERAÇÃo ENTRE OS ESPAÇOS CONSTITUCIONAIS NACIONAIS E INTERNACIONAIS E SEUS IMPACTOS NO SISTEMA DE FONTES DO DIREITO: AS LIÇÕES DA PROTEÇÃO COOPERATIVA DE DIREITOS HUMANOS E O CASO DA INTEGRAÇÃO EUROPEIA ...................................................... 173

Diego Fernandes Guimarães

WTO’s Engagement with National Law: Three Illustrations from India 193 Ravindra Pratap

GESTÃo MIGRATÓRIA E INTEGRAÇÃo REGIONAL: UMA ANÁLISE SOBRE A REGULAMENTAÇÃo NORmativa dos fluxos migratórios irregulares na União Europeia À luz do Novo Pacto Europeu sobre Migração e Asilo.................................................................. 212 João Mauricio Malta Cavalcante Filho e Eugênia Cristina Nilsen Ribeiro Barza

The African Regional Human and Peoples' Rights System: 40 years of progress and CHALLENGES. 232 Juan Bautista Cartes Rodríguez

The USMCA Sunset Clause 258 Jaime Tijmes-Ihl e Yvonne Georgina Tovar Silva

REFLEXÕES SOBRE A UNIVERSALIDADE DO DIREITO INTERNACIONAL DOS DIREITOS HUMANOS A RESPEITO DA PROTEÇÃO ÀS MULHERES 273 Érica Rios de Carvalho

A CRItical legal anAlysis OF GENDER EQUALITY IN INTERNATIONAL TRADE AgREEMENTS...287 Parul Shukla e Sheikh Sultan Aadil Huque

FEMinicídio, FEMicídio E Ódio NA AGENDA: o ASSASSinAto DAS MUlHERES NA AmÉriCA LATINA...... 309 Vinícius Ferreira Baptista

LEGAL IDEOLOGY IN THE CONTEXT OF DEVELOPMENT OF THE LEGAL STATE AND FORMATION OF THE CIVIL SOCIETY IN UKRAINE 
Direito INTERNACIONAL PÚBLICO NO ENTREgUERRAS (1919-39): A INSTITUCIONALIZAÇÃO DOS PROJETOS JURÍDICOS DE PAZ E MANEJO DOS POVOS NÃO SOBERANOS.

Hugo Luís Pena Ferreira

O Caso Gomes Lund (“Guerrilha Do Araguaia”) dez anos depois: Desafios para o cumPRIMENTO INTEGRAL PELO ESTADO BRASILEIRO

João Gabriel Archegas, Felipe Klein Gussoli e Vivian Cristina Lima López Valle

DiÁlogos museológicos: o Regime jurídico brasileiro e o Código de Ética do ConseLHo InTERnacional de Museus.

Paula Gonçalves do Carmo, Emerson Gabardo e Daniel Wunder Hachem 


\title{
Covid, Covax e o Refluxo da Governança Global*
}

\section{Covid, covax and the backflow of global governance}

\author{
Salem Hikmat Nasser** \\ Luiza Nogueira Papy***
}

\section{Resumo}

O caminho em direção à crescente globalização das relações sociais aparece como inexorável. Como parte desse percurso surgem múltiplas noções que implicam o reconhecimento de temas de interesse público comum e a necessidade de respostas coletivas. A Pandemia de Covid-19 faz, em certa medida, a prova da globalização e dos problemas comuns que colocam em risco o Bem Público Saúde. A resposta para a pandemia, materializada na forma de vacinas proclamadas como "bens públicos globais", emerge em conjunto com um mecanismo de Governança coletiva, a COVAX, incumbida da ambiciosa missão de universalizar o acesso ao imunizante. Este artigo parte de uma revisão bibliográfica da literatura dedicada aos Bens Públicos Globais para propor uma análise do problema de provisão global de vacinas contra o coronavírus centrada no mecanismo da COVAX. Organizado em três partes, o texto retraça, primeiramente, a noção de Governança Global e de conceitos correlatos para, então: (i) ponderar as implicações retóricas e práticas de se designar a vacina um BPG, (ii) estabelecer as premissas conceituais de BPG, e (iii) analisar a COVAX enquanto arranjo de governança global. Constata-se que, a despeito da retórica sobre a vacina e seu status, o funcionamento e os resultados da COVAX acabam por despi-la de suas aspirações inovadoras, e a revelam como pouco mais que um fórum de cooperação multilateral, constrangido pelo individualismo e nacionalismo de seus atores.

* Recebido em 31/05/2021

Aprovado em 27/09/2021

** Doutor em Direito Internacional pela Universidade de São Paulo (2004). E desde 2004, é professor nos cursos de Graduação e Pósgraduação de Direito Internacional na Escola de Direito da Fundação Getulio Vargas, em São Paulo. Atualmente, é também Coordenador do Centro de Direito Global da Direito GV. Email: salem.nasser@fgv.br

*** Mestranda no Programa de Mestrado e Doutorado Acadêmico em Direito e Desenvolvimento da Fundação Getúlio Vargas. Contemplada pela Bolsa Mario Henrique Simonsen de Ensino e Pesquisa do Programa de PósGraduação Stricto Sensu Acadêmico. E-mail: luizapapy@mac.com
Palavras-chave: Governança Global; Bens Públicos Globais; Globalização do Direito; Deglobalização.

\section{Abstract}

The road towards an ever-growing globalization of social interactions has for a time seemed inexorable. As a part of this path, several notions have emerged, all of which imply the recognition that there are problems of public interest which demand collective answers. The Covid-19 Pandemic serves, up to a certain extent, as a proof of globalization and of the menace against a Global Public Good (GPG), which is Health. The answer thereto provided takes the shape of vaccines broadly advertised as "global public goods" and emerge along a collective governance mechanism - COVAX 
- tasked with the ambitious mission of providing universal access to the immunizing substance. Ignited by such polyphonous talks, this article undertakes a bibliographical revision concerning Global Public Goods in order to analyze the global vaccine provision problem encompassed in the COVAX mechanism. This threefolded article begins by recalling the notion of Global Governance and its related concepts, and proceeds to (I) ponder on the rhetorical and practical implications of addressing a vaccine as a GPG, (ii) presenting the concept of GPG, and (iii) analyzing COVAX as a global governance structure. Once the path is travelled, the authors conclude that, despite the rhetoric concerning the vaccine and its status, the results provided by the COVAX mechanism appear to only one more multilateral cooperation forum, crippled by its actors' individualistic and nationalistic choices.

Keywords: Global Governance; Global Public Goods; Globalization of Law; Deglobalization.

\section{Introdução}

O COVAX (Covid-19 Vaccine Access) nasce no conturbado cenário do enfrentamento à pandemia de COVID-19. Sem contornos precisos, esse mecanismo de governança coletiva reúne atores públicos e privados, estatais e não estatais com um objetivo comum: a provisão de vacinas capazes de pôr fim à pandemia.

Nada espontânea, a construção deste mecanismo se dá com base em fundamentos práticos e teóricos importantes. Os práticos, que incluem todas as mazelas decorrentes da pandemia, por serem evidentes e conhecidos, não serão tratados neste trabalho. Os teóricos, por sua vez, serão explorados neste artigo com o intuito de se demonstrarem a profusão de conceitos e noções mobilizados em torno de uma iniciativa real como o COVAX ${ }^{1}$.

\footnotetext{
${ }^{1}$ Considerando que a iniciativa do COVAX é extremamente recente e está em constante evolução, e que os documentos informativos sobre sua constituição e estrutura são escassos e possuem restrições quanto a serem referenciados em publicações, os autores deste artigo contam com a complacência de seus leitores e leitoras no que concerne à limitação das descrições sobre o COVAX aqui fornecidas. Para mais informações sobre o COVAX, sugerimos acessar: https://www.gavi.org/covax-facility\#what. https://www.gavi.org/ vaccineswork/covax-explained.
}

Assim, tomando por caso concreto o mecanismo de governança coletiva COVAX, esse trabalho propõe-se a analisar em que medida a resposta prática ao problema da provisão global de vacinas contra o coronavírus corresponde às considerações teóricas relativas à globalização, à governança global e aos bens públicos globais.

Se há uma constante na evolução das relações internacionais e na sua regulação — em sentido lato, enquanto organização por via de criação e aplicação de normas, regras - esta, talvez, seja um avanço permanente em direção à maior interdependência entre os atores sociais e ao reconhecimento de espaços, interesses, bens, destinos, ditos todos "comuns".

Se pensadas as relações como sendo aquelas que envolvem apenas, ou essencialmente, os Estados, e se concebida a regulação como aquela dada apenas, ou essencialmente, pelo Direito Internacional Público, pode-se falar da crescente interdependência entre os países e do reconhecimento de espaços ditos internacionais ou internacionalizados, que não são passíveis de apropriação territorial e/ou de uso livre para todos os membros da sociedade. Esses espaços, muitas vezes chamados de "patrimônio da humanidade", organizam-se em torno de interesses compartilhados, que comandam um senso de cooperação a ser instilado na ordem jurídica e a inspirar também o que está fora dela. Nessa visão, vislumbra-se um destino comum em que a sobrevida no planeta depende, absolutamente, de uma real cooperação, a ser traduzida no Direito.

Outra constante das relações internacionais, no entanto, afirma que, ao menos desde que se formou o Estado Nacional e o sistema de Estados, é possível notar uma progressiva emergência em importância de outros atores sociais, que não os Estados. As interações envolvendo esses outros atores são crescentemente vistas como objeto de análise e compreensão necessárias para quem pretende explicar ou representar com maior acuidade o funcionamento do mundo. Também esses atores passam a participar da identificação, ou da construção, daquelas coisas, espaços, interesses, bens e destino, considerados comuns a uma sociedade ampliada, por assim dizer.

Não apenas isso. Esses outros atores participam, também, da regulação da vida nessa sociedade ampliada, dita global, produzindo normas, gerenciando e aplicando-as, criando e operando instituições. 
Evidentemente, a maior importância dos atores não estatais não decorre de um ato de vontade ou de uma mera escolha metodológica, de uma calibragem do olhar — ainda que, sim, sempre se possa delimitar ângulos de visão e perspectivas. Essa crescente importância decorre de um processo natural de intensificação, diversificação e complexificação das interações sociais num mundo globalizado, cada vez menor, coberto por uma manta cada vez mais espessa de trocas e fluxos.

As interações sociais serão sempre, necessariamente, acompanhadas por alguma regulação, ainda que as regras sejam fluidas e incertas, e decorram da regularidade dos comportamentos e da relação dos atores com essa regularidade. Haverá, portanto, regulação desse novo mundo ou, talvez, devamos dizer, "há" esta regulação².

Porque os direitos nacionais, estatais, são naturalmente voltados à organização da vida dentro das fronteiras do Estado, e apenas marginalmente incidem sobre o que se passa fora do seu território; e porque o Direito Internacional Público, ainda que voltado cada vez mais para a cooperação e para a resposta aos desafios coletivos, continua a ser um Direito produzido pelos Estados e destinado a regular o comportamento desses mesmos Estados, nem um nem outro desses dois tipos de Direito parece apto a dar conta sozinho do que é comum a uma sociedade internacional ampliada e muito mais complexa.

Já se disse que o recurso à noção de governança era, a um só tempo, uma fuga do Estado e uma fuga do Direito $^{3}$. Em parte, à luz do que se expôs acima, parece justificada essa dupla fuga, já que a complexidade das relações somada à riqueza dos fenômenos de regulação demanda uma chave interpretativa diferente. Uma, que tenda a compreender como são organizadas as interações sociais para além do Direito e de tudo aquilo que os Estados produzem - quer se trate de Direito, quer

\footnotetext{
${ }^{2}$ KACOWICZ, Arie M. Global Governance, International Order, and World Order. In: LEVI-FAUR, David (ed.). Oxford Handbook of Governance. [S. 1.]: Oxford University Press, 2012., Chap. 48. NASSER, Salem Hikmat; GHIRARDI, José Garcez. Around the pyramid: Political-theoretical challenges to law in the age of global governance. Revista de Direito Internacional, v. 15, n. 1, p. 61-69, 2018. DOI: https://doi.org/10.5102/rdi.v15i1.4934.

3 NASSER, Salem Hikmat. GHIRADI, José Garcez. O que se diz e que se cala: a governança entre a fuga do direito e a busca pelo controle. Revista do Programa de Pós-graduação em Direito da UFC, v. 38, n. 2, p. 731-744, jul./dez. 2018. Disponível em: http://www.periodicos. ufc.br/nomos/article/view/3981. Acesso em: set. 2021.
}

de regulação não-jurídica, mas ainda assim, produzida pelo Estado ${ }^{4}$.

O recurso a uma noção mais abrangente, que queira marcar o distanciamento ou, ao menos, a distinção em relação ao que é do Estado sem, contudo, deixar de incluir em sua designação a ordenação das relações sociais promovida pela autoridade estatal, aparece como algo natural, talvez até mesmo necessário. Não por acaso, a palavra "governança" se aproxima ao mesmo tempo em que se quer diversa de "governo", termo que designa a ordenação das relações sociais realizada pelo Estado.

A alternativa terminológica, no entanto, não resolve todos os problemas que questões conceituais podem colocar. Já se apontou, por exemplo, para o fato de que os mecanismos de governança não estão libertos dos jogos de poder — podem, inclusive, ser loci de maior dificuldade no enfrentamento destes mesmos jogos não afastam questionamentos sobre sua legitimidade e sua justiça intrínseca ${ }^{6}$, assim como não são necessariamente respostas que podem ser tidas como "naturais" ou mais eficientes para problemas ${ }^{7}$.

Há quem afirme que muito da governança global pode ser entendida como ação administrativa ${ }^{8}$. E nessa senda, aponte para a constituição de um "espaço

${ }^{4}$ NASSER, Salem Hikmat. Fontes e Normas do Direito Internacional: Um Estudo sobre a Soft Law. 2. ed. São Paulo: Editora Atlas, 2006. NASSER, Salem Hikmat. Direito Global em Pedaços: Fragmentação, Regimes e Pluralismo. Revista de Direito Internacional, v. 12, n. 2 , p. 126, 2015. DOI: $10.5102 /$ rdi.v12i2.3707

5 Sobre conceituação de governança "sem governo", ver: SLAUGHTER, A-M. The Real New World Order. Foreign Affairs, v. 76, n. 5, 1997, p. 184; e KACOWICZ, Arie M. Global Governance, International Order, and World Order. In: LEVI-FAUR, David (ed.). Oxford Handbook of Governance. [S. l.]: Oxford University Press, 2012. ${ }^{6}$ Nesse sentido, Ost e Kerchov apontam como discurso sobre governança global não pode existir em uma narrativa neutra. Cf. OST, François; KERCHOVE, Michel van de. De la pyramide au réseau? Pour une théorie dialectique du droit. Bruxelles: Presses des Facultés Universitaires Saint-Louis, 2002

NASSER, Salem Hikmat. O que se diz e que se cala: a governança entre a fuga do direito e a busca pelo controle. Revista do Programa de Pós-graduação em Direito da UFC, v. 38, n. 2, p. 731-744, jul./dez. 2018. ${ }^{8}$ CASSESE, S. Global Administrative Law: An Introduction. IIJL Conference. Anais, 2005. p. 1-46. Vide também: KINGSBURY, B. et al. Foreword: Global Governance as Administration - National and Transnational Approaches to Global Administrative Law. Law and Contemporary Problems, v. 68, n. 3-4, p. 1-13, 2005; KRISCH, N.; KINGSBURY, B. Introduction: Global Governance and Global Administrative Law in the International Legal Order. European Journal of International Law, v. 17, n. 1, p. 1-13, 2006. DOI: 10.1093/ejil/ chi170 
administrativo global" e para a ação administrativa" - entendida como produção normativa, resolução de controvérsias e outros tipos de regulação tipicamente administrativa - cujos produtores seriam atores diversos, operando em esferas diferentes, muitas vezes em esquemas que colocam esses produtores em algum tipo de colaboração ${ }^{10}$. Tratar-se-ia, portanto, de uma espécie de executivo global pulverizado, distribuído, descentralizado. A ideia de que um executivo tenha esse desenho desponta como inusual e estranha por si só, mas parece compreensível que se queira referir sobretudo a natureza "administrativa" das ações, e não do corpo que age. $\mathrm{O}$ que leva ao seguinte questionamento: o que faz com que uma ação de governança mereça o adjetivo "administrativa"?

A inclusão da regulação privada transnacional entre os tipos de produção administrativa global, complementada pela própria literatura específica sobre essa regulação privada, dá uma pista: a regulação que interessa não é aquela que atinge os interesses meramente privados, mas sim aquela que envolve e impacta interesses públicos $^{11}$.

Quando se diz que esse é o tipo de regulação privada que interessa, considera-se que essa literatura quer fundamentalmente discutir a legitimidade da regulação, sua

\footnotetext{
${ }^{9}$ KINGSBURY, B.; KRISCH, N.; STEWART, R. B. The Emergence of Global Administrative Law. Law and Contemporary Problems, v. 68 , p. $15-61,2005$. p. 17

${ }^{10}$ Sobre os arranjos híbridos de atores no âmbito do Direito Administrativo Global, cf. KINGSBURY, B.; KRISCH, N.; STEWART, R. B. The Emergence of Global Administrative Law. Law and Contemporary Problems, v. 68, p. 15-61, 2005. p. 22

11 Sobre regulação privada transnacional: Ver ABBOTT, K. W.;SNIDAL D. Strengthening International Regulation through Transnational New Governance: Overcoming the Orchestration Deficit. Vanderbilt Journal of Transnational Law, p. 1-69, 2009; BARTLEY, T. Institutional Emergence in an Era of Globalization:The Rise of Transnational Private Regulation of La- bor and Environmental Conditions. American Journal of Sociology, v. 113, n. 2, p. 297-351, 2007.; BENVENISTI, E.; DOWNS, G. W. National Courts Review of Transnational Private Regulation, n. 2003, p. 1-18, 2005. (working paper) Disponível em: <http://papers. ssrn.com/sol3/papers. cfm?abstract_id=1742452>; CAFAGGI, F. New Foundations of Transnational Private Regulation. Journal of Law and Society, v. 38, n. 1, p. 20-49, 2011; NASSER, Salem Hikmat. Direito Global em Pedaços: Fragmentação, Regimes e Pluralismo. Revista de Direito Internacional, v. 12, n. 2, p. 127-128, 2015. PETERSMANN, ErnstUlrich. Multilevel governance of Interdependent public goods theories, rules and institutions for the central policy challenges in the 21st Century. Global Governance, v. RSCAS 2010, n. 2, p. 30, 2010. DOI: $10.2139 /$ ssrn.2481918. Available at: https://cadmus. eui.eu/bitstream/handle/1814/22275/RSCAS_2012_23final. pdf? sequence $=2 \&$ is Allowed $=\mathrm{y}$
}

responsividade aos diversos interesses envolvidos, aos seus mecanismos de transparência etc. Posto de modo diverso, pode-se concluir que a literatura sobre a ação administrativa global está focada na necessidade de que venha a emergir um Direito Administrativo Global que possa aferir essas mesmas coisas no comportamento dos administradores distribuídos, e controlar as suas ações $^{12}$.

Parece, no entanto, que a vontade de ver emergir um tal Direito Administrativo ou a afirmação da necessidade de tal emergência não são suficientes para fazer com que este se materialize, e tampouco resolve o problema sobre como ou quem controlará o que fazem esses diversos "administradores".

Do mesmo modo, a noção de uma "Autoridade Pública Internacional" que se poderia atribuir a alguns atores quando a sua ação é dirigida a temas de interesse público $^{13}$ não resolve, de modo satisfatório, a questão fundamental sobre quem regula o regulador, e quem controla o controlador.

No mesmo sentido, é importante relembrar que nem tudo o que é de "interesse público" é necessariamente de "alcance global". Na maior parte das vezes, esses administradores (incluídos os reguladores privados ${ }^{14}$ ) pulverizados pelo globo, respondem a temas que envolvem interesse público por dizerem respeito a partes interessadas várias.

Quando as partes interessadas podem ser identificadas como a sociedade internacional em seu todo, ou de maneira mais abrangente, como a humanidade, tem-se o Bem Público Global. Talvez um dos mais evidentes e indiscutíveis bens públicos globais que se possa

12 SANCHEZ, M. R. The Global Administrative Law Project: A review from Brazil. Artigos Direito GV. 1 Oct. 2008. DOI: http:// dx.doi.org/10.2139/ssrn.1483379

13 Sobre Autoridade Pública Internacional (International Public Authority), ver: VON BOGDANDY, A. General Principles of International Public Authority: Sketching a Research Field. German Law Journal, v. 9, n. 11, p. 1909-1939, 2008. DOI: 10.1017/S2071832200000699; VON BOGDANDY, A., DANN, P., GOLDMANN, M. Developing the Publicness of Public International Law: Towards a Legal Framework for Global Governance Activities. German Law Journal, v. 9, n. 11, p. 1375-1400, 2008. DOI:10.1017/S2071832200000511

${ }_{14}$ Sobre a participação de reguladores privados e não-estatais, vide neste mesmo periódico: PORTO, Gabriela Hühne; ALMEIDA, Paula Wojcikiewicz; NETTO, Juliana Maria F.A. International Regulation and Global Governance: the EU influential method in times of normativity change. Brazilian Journal of International Law, v. 17, n. 1, p. 373-390, 2020. Disponível em: https://doi.org/10.5102/rdi. v17i1.6167. Acesso em: set. 2021. 
conceber, e um que dialogue com as preocupações da atualidade, seja aquele da proteção do clima, como parte de um equilíbrio ecológico sem o qual a vida na Terra não pode prosperar. ${ }^{15} \mathrm{~A}$ clareza decorre do fato de que interessa certamente a todos (é, na verdade, vital para todos, gerações futuras incluídas) que, estando presente, tal bem possa ser usufruído por todos e seus benefícios sejam gozados igualmente por todo e qualquer ser vivo. O clima ou o equilíbrio ecológico respondem, portanto, ao critério de interesse público, ao critério de alcance global e aos critérios concebidos como marcas dos bens públicos globais, a não-rivalidade e a não-excludência, como se verá adiante.

Do mesmo modo, a Teoria de BPG sustenta que, também, a Saúde Global possa ser vista como um bem público global ${ }^{16}$, ainda que a necessidade de com ela lidar no plano global seja mais decorrente da contingência das trocas e dos fluxos transnacionais. $\mathrm{O}$ maior contato, portanto, e a maior comunicação entre as pessoas fazem com que as doenças já não sejam facilmente controladas localmente. O seu alcance global é também uma decorrência de decisões (policy choices) de lidar com ela globalmente ${ }^{17}$.

No momento em que se escreve, o mundo enfrenta uma pandemia que é a própria materialização de um problema de saúde global prenunciado há tempos ${ }^{18}$. E

\footnotetext{
15 Sobre a abordagem da proteção ao Meio Ambiente enquanto Bem Público Global, ver: SHAFFER, Gregory. International law and global public goods in a legal pluralist world. European Journal of International Law, v. 23, n. 3, p. 669-693, 2012. https://doi. org/10.1093/ejil/chs036; BRATSPIES, Rebecca M. Providing global public goods under uncertainty. American Society of International Law Proceedings, v. 104, n. 9-10, p. 591-603, 2010. Disponível em: https://doi.org/10.1016/j.jpubeco.2010.06.008. Acesso em: set. 2021.

${ }^{16}$ CHEN, Lincoln C., EVANS, Tim G., CASH, Richard A. Health as a Global Public Good. In KAUL, Inge; GRÜNBERG, Isabelle; STERN, Marc A. Global Public Goods: International Cooperation on the 21st Century. New York: Oxford University Press, 1999.

17 ARHIN-TENKORANG, Dyna; CONCEIÇÃO, Pedro. Beyond Communicable Disease Control: Health in the Age of Globalization. In. KAUL, Inge; CONCEICAO, Pedro; LE GOULVEN, Katell; MENDOZA, Ronald U. Providing Global Goods. New York: Oxford University Press (OUP), 2003. DOI: 10.1093/0195157400.001.0001. 18 GERHART, Peter in MASKUS, Keith E.; REICHMAN, Jerome H. International Public Goods and Transfer of Technology under a Globalized Intellectual Property Regime. Cambridge: Cambridge University Press (CUP), 2005. p. 72-73. HALE, Thomas; HELD, David; YOUNG, Kevin. Gridlock: Why Global Cooperation is Failing When We Need it Most. Cambridge: Polity, 2013. p. 103-106. KAUL, Inge; CONCEIÇÃO, Pedro; LE GOULVEN, Katell; MENDOZA, Ronald U. Providing Global Public Goods. New York: Oxford University Press (OUP), 2013. p. 390-392.
}

essa mesma pandemia se mostra um potente revelador das falhas e das faltas dos esquemas de governança global, inclusive naquela parte da governança que é responsabilidade dos Estados e do Direito Internacional ${ }^{19}$, ao mesmo tempo em que paradoxalmente, revela a inexorabilidade da globalização e da interdependência.

Mais do que isso, ela tornou patente o fato de que a existência de um problema global e o seu reconhecimento generalizado não são suficientes para produzir as respostas coletivas que se fazem necessárias. Pelo contrário, o que se assistiu, no caso da pandemia de COVID-19, foi uma regressão da cooperação e um ressurgir do individualismo dos Estados, e não só deles ${ }^{20}$.

Dado o panorama maior, passa-se a (i) ponderar as implicações retóricas e práticas de se designar a vacina enquanto BPG, (ii) esclarecer as premissas do conceito de BPG, e (iii) analisar o COVAX enquanto arranjo de governança global.

\section{Haja vacina: da retórica à prática de vacinas enquanto BPGs}

O desdobramento do anúncio da Pandemia de COVID-19, em 11 de março de 2020, foi marcado por descoordenação política e não poucos atritos diplomáticos, no plano internacional. No entanto, uma ideia mostrou-se recorrente nos discursos de diversos chefes de Estado: a necessidade de se criar, com urgência, uma vacina segura e eficaz, que fosse um Bem Público Global (BPG) ${ }^{21}$.

19 PETERSMANN, Ernst-Ulrich. International Economic Law and "Public REason": Why do governments fail to protect International Public Goods more effectively? European University Institute, Florenza, v. 17, n. 1, p. 28-36, 2010.

${ }^{20}$ IKENBERRY, G. John. The Next Liberal Order: The Age of Contagion Demands More Internationalism, Not Less. Foreign Affairs, Jul./Aug. 2020. Disponivel em: https://www.foreignaffairs.com/articles/united-states/2020-06-09/next-liberal-order. Acesso em : 23 set. 2021. BOLLYKY, Thomas J; BOWN, Chad P; CAMPBELL, Joseph. The Tragedy of Vaccine Nationalism: Only Cooperation Can End the Pandemic. Foreign Affairs, jul. 2020. Disponível em: https://www.foreignaffairs.com/articles/unitedstates/2020-07-27/vaccine-nationalism-pandemic. Acesso em: 22 set. 2021. FIDLER, David P. Vaccine nationalism's politics. Science, v. 369, n. 6505, p. 749, 2020. DOI: https://doi.org/10.1126/science. abe 2275

${ }^{21} \mathrm{O}$ presidente chinês, Xi Jinping pronunciou-se neste sentido na $73^{\mathrm{a}}$ Assembleia Geral da OMS, em maio 2020, cf. ZHAOYI, Pan. Chinese vaccines will be made global public good, says Xi. CGNT, 19 maio 2020. Disponível em: https://news.cgtn.com/news/2020-05-19/ Chinese-vaccines-will-be-made-global-public-good-says-Xi-QCpF- 
A expressão, quase autoexplicativa, soa bem nos palanques políticos, mas camufla importantes implicações teóricas e consequências político-normativas ${ }^{22}$. A mera declaração de que se deve desenvolver vacinas e torná-las bens públicos globais nada diz sobre os arranjos necessários para o desenvolvimento, produção e distribuição delas em tempo recorde e escala sem precedentes. O conceito tampouco indica como devem ser conciliados os interesses potencialmente conflitantes de (todos os) países e de atores não estatais, como as organizações internacionais, indústrias farmacêuticas e investidores.

Por ocasião da $73^{\mathrm{a}}$ Assembleia Geral da Organização Mundial de Saúde (OMS), em maio de 2020, e em outros eventos naquele ano, líderes políticos das mais variadas matizes e representantes da sociedade civil rogaram por uma vacina contra o coronavírus que fosse um "bem público global" (BPG) ${ }^{23}$. Embora o clamor fosse praticamente o mesmo, as significações e consequências políticas dessas declarações variam conforme seu enunciador.

De um lado, tem-se representantes de países de baixa renda, tais como os presidentes do Gana, Paquistão e o líder da União Africana, para os quais a realidade de uma vacina passa, necessariamente, por um arranjo multilateral forte, capaz de garantir o desenvolvimento, o acesso e a distribuição do produto final vacina. De outro lado, há chefes de Estado de países com alto poder aquisitivo, como Alemanha, Reino Unido e França, para os quais o conceito de BPG carrega significado políti-

SGIL2g/index.html Acesso em: 31 maio 2021. Também a chanceler alemã, Angela Merkel e o presidente francês, Emmanuel Macron, fizeram declarações semelhantes, porém na Conferência da GAVI, um mês mais tarde, cf. MESSAGE du Président Emmanuel Macron lors du Sommet mondial sur la vaccination 2020. Élysée, 04 jun 2020. Disponível em: https://www.elysee.fr/emmanuel-macron/2020/06/04/message-du-president-emmanuel-macron-lorsdu-sommet-mondial-sur-la-vaccination-2020-alliance-du-vaccingavi Acesso em: 31maio 2021.

${ }^{22}$ LONG, David; WOOLLEY, Frances. Global Public Goods: Critique of a UN Discourse. Global Governance, v. 15, n. 1, p. 107-122, 2009. DOI: https://doi.org/10.1163/19426720-01501007.

23 PHELAN, Alexandra L.; ECCLESTON-TURNER, Mark; ROURKE, Michelle; MALECHE, Allan; WANG, Chenguang. Legal agreements: barriers and enablers to global equitable COVID-19 vaccine access. The Lancet, v. 396, n. 10254, p. 800-802, 2020. DOI: https://doi.org/10.1016/S0140-6736(20)31873-0. BOLLYKY, Thomas J; BOWN, Chad P; CAMPBELL, Joseph. The Tragedy of Vaccine Nationalism: Only Cooperation Can End the Pandemic. Foreign Affairs, jul. 2020. Disponível em: https://www.foreignaffairs. $\mathrm{com} /$ articles/united-states/2020-07-27/vaccine-nationalism-pandemic. Acesso em: 22 set. 2021. FIDLER, David P. Vaccine nationalism's politics. Science, v. 369, n. 6505, p. 749, 2020. DOI: https:// doi.org/10.1126/science.abe2275. co consolidado no sentido de legitimar suas práticas de política externa na forma de auxílio ao desenvolvimento

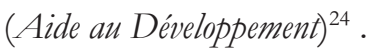

De maneira que, no discurso do presidente francês, Emmanuel Macron, proferido na Reunião de Cúpula da $\mathrm{GAVI}^{25}$, em junho de 2020, a afirmação de que as vacinas haveriam de ser BPGs acenava para uma iniciativa de universalização do acesso à vacina. Já o presidente chinês Xi Jinping, em seu pronunciamento na $73^{\mathrm{a}}$ Assembleia Geral da OMS, declarou que "uma vez disponíveis, as vacinas desenvolvidas na China se tornariam bens públicos globais e que esta seria a contribuição da China para garantir acessibilidade material e financeira das vacinas aos países em desenvolvimento"26. Um prenúncio, portanto, das iniciativas unilaterais de distribuição de vacinas que o país viria a praticar ${ }^{27}$.

${ }^{24}$ MINISTERE DES AFFAIRES ÉTRANGERES. Les biens publics mondiaux. [S. 1.]: Ministère des Affaires étrangères, févr. 2002. Disponível em: https://www.diplomatie.gouv.fr/IMG/pdf/Les_biens_publics_mondiaux-2.pdf. Acesso em: 22 set. 2021. CARBONE, Maurizio. Supporting or Resisting Global Public Goods? The Policy Dimension of a Contested Concept. Global Governance, v. 13, n. 2, p. 183, 2007. FREUD, Claude. Les biens publics mondiaux. Cabiers d'études africaines, v. 50, n. 198-199-200, p. 1067-1077, 2010. DOI: https://doi.org/10.4000/etudesafricaines.16481.

25 «Le deuxième enjeu, c'est de faire en sorte dès maintenant qu'un vaccin contre le COVID-19, lorsqu'il sera découvert, bénéficie à tous, parce qu'il sera un bien public mondial. C'est l'un des objectifs essentiels de l'initiative ACT-A que nous avons portée avec l'organisation mondiale de la santé, la Commission européenne, le Royaume-Uni et bien d'autres et qui trouve aujourd'hui, au travers de cette conférence, une nouvelle traduction concrete. C'est pourquoi la France sera prête, comme le demande l'alliance, à augmenter de 100 millions d'euros sa contribution lorsqu'un vaccin efficace contre le COVID-19 sera disponible, afin d'en assurer la diffusion à un prix abordable tout en maintenant le niveau d'engagement nécessaire contre les autres maladies.» MESSAGE du Président Emmanuel Macron lors du Sommet mondial sur la vaccination 2020. Élysée, 04 jun 2020. Disponível em: https://www.elysee.fr/ emmanuel-macron/2020/06/04/message-du-president-emmanuelmacron-lors-du-sommet-mondial-sur-la-vaccination-2020-alliancedu-vaccin-gavi . Acesso em: 31 maio 2021.

26 "COVID-19 vaccine development and deployment in China, when available, will be made a global public good, which will be China's contribution to ensuring vaccine accessibility and affordability in developing countries." ZHAOYI, Pan. Chinese vaccines will be made global public good, says Xi. CGNT, 19 maio 2020. Disponível em: https://news.cgtn.com/news/2020-05-19/Chinese-vaccines-willbe-made-global-public-good-says-Xi-QCpFSGIL2g/index.html Acesso em: 31 maio 2021.

27 Esta prática, cunhada como "Diplomacia da vacina" (Vaccine Diplomacy), tem-se popularizado entre os países com capacidade de produção de vacina. Vide: PRANGE, Astrid. A diplomacia da vacina vai melhorar a imagem da China? DW, 25 fev. 2021. Disponível em: https://p.dw.com/p/3pvWg . Acesso em: 31 maio 2021. GUIMARÃES, Maria João. Israel dá vacinas à República Checa, que vai abrir representação diplomática em Jerusalém. Disponível em: https://www.publico. 
Há, ainda, países de renda média, como África do Sul, Índia e Brasil que, embora não sejam abastados ao ponto de assegurar, de antemão ${ }^{28}$, vacinas para suas numerosas populações, são atraentes de um ponto de vista comercial, pois têm condições de comprar consideráveis quantias de doses e de reproduzir os imunizantes nacionalmente. Para estes, arranjos de cooperação multilateral que prevejam transferência de tecnologia ${ }^{29}$ e condições facilitadas de pagamento são interessantes.

Essas distinções ilustram o quão ambivalente e ambíguo pode ser o conceito de Bem Público Global, ao mesmo tempo que revelam uma importante premissa. $\mathrm{O}$ conceito de BPG deve trazer coerência às políticas públicas nacionais e de cooperação internacional, e ainda promover um vínculo entre as concepções de unilateralismo, bilateralismo, regionalismo e multilateralismo ${ }^{30}$. Ao empregarem-no, portanto, os líderes políticos usaram mais que um recurso retórico, mobilizaram toda uma teoria.

\section{BPG: origem e premissa conceitual}

"Global public goods are goods, whose benefits or costs are of nearly universal reach or potentially affecting anyone anywhere."

pt/2021/02/24/mundo/noticia/israel-vacinas-republica-checa-vaiabrir-representacao-diplomatica-jerusalem-1951935. Acesso em: 31 maio 2021. MARLOW, I.; CHAUDHARY, A.; LINDBERG, K. S. India Beats China atIts Own Game in Vaccine Diplomacy Fight. Bloomberg, 25 fev. 2021. Disponível em: https://www.bloomberg.com/ news/articles/2021-02-25/india-beats-china-at-its-own-game-invaccine-diplomacy-battle. Acesso em: 31 maio 2021.

28 Isso contrasta com a atitude de muitos países desenvolvidos com alto poder aquisitivo ou de países em desenvolvimento, porém pouco populosos, que têm assegurado quantias exageradas de imunizantes para seus cidadãos. A título de exemplo, vide: https://veja. abril.com.br/mundo/covid-19-paises-ricos-compraram-mais-dametade-dos-estoques-de-vacinas/; https://www.theguardian.com/ world/2021/jan/29/canada-and-uk-among-countries-with-mostvaccine-doses-ordered-per-person. Acesso em: set. 2021.

${ }^{29}$ De fato, o Brasil tem produzido a vacina batizada Coronavac graças a um acordo de transferência de tecnologia celebrado entre a farmacêutica chinesa Sinovac Life Science e o Instituto Butantan. A propósito, ver: https://butantan.gov.br/noticias/governo-de-spassina-contrato-com-sinovac-para-o-fornecimento-de-46-milhoesde-doses-da-coronavac Acesso em: set. 2021.

${ }^{30}$ GABAS, Jean-Jacques; HUGON, Philippe. Les biens publics mondiaux et la coopération internationale. L'Économie politique, v. 12, n. 4, p. 19-31, 2001. DOI: https://doi.org/10.3917/leco.012.0019. BOIDIN, Bruno; HIEZ, David; ROUSSEAU, Sandrine. Biens communs, biens publics mondiaux et propriété. Introduction au dossier. Développement durable et territoires, Dossier 10, p. 5, 2008.
As origens do conceito remontam à distinção estabelecida pelo economista Paul Samuelson ${ }^{31}$ entre Bens Privados e Bens Públicos, em sua "The Pure Theory of Public Expenditure", publicada na década de 1950. Por serem não rivais (non-rival) e não excludentes (non-excludable) em seu consumo, Samuelson identifica que os bens públicos sofrem de um problema crônico de produção deficitária, consequência das várias externalidades negativas que lhes são características. Ainda no campo das ciências econômicas, Mancur Olson ${ }^{32}$ (1965) elaborou a relação entre as externalidades provocadas pelos bens públicos e as dinâmicas de cooperação necessárias para sua provisão ${ }^{33}$, mas é a Garrett Hardin (1968) e Charles Kindleberger (1986) que se atribui a transposição do conceito de bens públicos nacionais à esfera global ${ }^{34}$.

Essa transposição decorre da constatação de que o alto grau de globalização que o mundo vivencia gera problemas globais, cujas consequências ultrapassam limites espaciais (são transnacionais) e temporais (são transgeracionais $)^{35}$. De tal maneira que se pode identificar males públicos globais (global public bads), geradores de custos em escala global, tais como o aquecimento glo-

31 NORDHAUS, William D. Paul Samuelson and global public goods: A commemorative essay for Paul Samuelson. Samuelsonian economics and the twenty-first century Oxford: Oxford University Press, 2006. DOI: https://doi.org/10.1093/acprof:o so/9780199298839.003.0006

32 OLSON, Mancur. The Logic of Collective Action: Public Goods and The Theory of Groups. Cambridge: Harvard University Press, 1965. 33 BARRET, Scott. Why Cooperate? The Incentive to Supply Global Public Goods. [S. 1.]: Oxford University Press, 2007. DOI: https:// doi.org/10.11126/stanford/9780804781329.003.0004.

${ }^{34}$ KINDLEBERGER, Charles. International Public Goods without International Government. American Economic Review, v. 76, n. 1, p. 1-13, 1986. KAUL, Inge; GRÜNBERG, Isabelle; STERN, Marc A. Global Public Goods: International Cooperation on the 21st Century. New York: Oxford University Press, 1999. BARRET, Scott. Why Cooperate? The Incentive to Supply Global Public Goods. [S. 1.]: Oxford University Press, 2007. DOI: https://doi.org/10.11126/ stanford/9780804781329.003.0004. BOIDIN, Bruno; HIEZ, David; ROUSSEAU, Sandrine. Biens communs, biens publics mondiaux et propriété. Introduction au dossier. Développement durable et territoires, Dossier 10, p. 0-11, 2008. DOI: https://doi.org/10.4000/ developpementdurable.5153. CAFAGGI, Fabrizio; CARON, David D. Global public goods amidst a plurality of legal orders: A symposium. European Journal of International Law, v. 23, n. 3, p. 643-649, 2012. DOI: https://doi.org/10.1093/ejil/chs049

35 SANDLER, Todd in KAUL, Inge; GRÜNBERG, Isabelle; STERN, Marc A. Global Public Goods: International Cooperation on the 21st Century. New York: Oxford University Press, 1999. BARRET, Scott. Why Cooperate? The Incentive to Supply Global Public Goods. [S. 1.]: Oxford University Press, 2007. DOI: https://doi. org/10.11126/stanford/9780804781329.003.0004. 
bal e, evidentemente, a pandemia de coronavírus, mas também a própria ausência ou insuficiência de bens públicos. Esses males são, por sua vez, remediados pela provisão de bens públicos globais (global public goods), geradores de benefícios em escala global. Ou seja, pela elaboração de arranjos institucionais que vão além dos tradicionais instrumentos de produção de bens públicos nacionais. Nesse sentido,

\section{National public goods become transnational - re- gional or global - when they cannot be maintained or improved solely through domestic policy action. Thus global public goods can be seen as compri- sing national public goods plus international coo- peration..$^{36}$.}

A partir dessa premissa de que problemas (ou males) globais demandam soluções globais, a Teoria de Bens Públicos Globais ${ }^{37}$ propõe duas abordagens conceituais com consequências distintas para a cooperação internacional $^{38}$. A primeira é uma abordagem em termos de falhas de mercado (Market failures), que explica o déficit na produção de BPGs a partir da dinâmica de incentivos e externalidades negativas ${ }^{39}$, e requer a implementação de

\footnotetext{
36 BARRET, Scott. Creating Incentives for Cooperation: Strategic Choices. In: KAUL, Inge; CONCEIÇÃO, Pedro; LE GOULVEN, Katell; MENDOZA, Ronald U. Providing Global Public Goods. [S. 1.: s. n.], 2013. v. 01. p. 332

${ }^{37}$ Note-se que o termo Bem Público Global, traduzido da expressão anglófona "Global Public Goods", é o mais frequente na literatura especializada e será aqui empregado como sinônimo das variantes "bens públicos mundiais" (comum na literatura francófona), "bens públicos internacionais", e ainda, como "bens públicos da humanidade". GIANNATTASIO, Arthur Roberto Capella; PAPY, Luiza Nogueira; NIGRO, Renan Freire. Bens Públicos Globais e sua proteção jurídica internacional: relocalização epistemológica de um debate à luz de princípios de direito político. Direito, Estado e Sociedade, n. 55, p. 69-112, 2019.
}

${ }^{38}$ GABAS, Jean-Jacques; HUGON, Philippe. Les biens publics mondiaux et la coopération internationale. L'Économie politique, v. 12, n. 4 , p. 23,2001

39 SANDLER, Todd in KAUL, Inge; GRÜNBERG, Isabelle; STERN, Marc A. Global Public Goods: International Cooperation on the 21st Century. New York: Oxford University Press, 1999. DO I:10.1093/0195130529.003.0002. GABAS, Jean-Jacques; HUGON, Philippe. Les biens publics mondiaux et la coopération internationale. L'Économie politique, v. 12, n. 4, p. 23, 2001. BOIDIN, Bruno; HIEZ, David; ROUSSEAU, Sandrine. Biens communs, biens publics mondiaux et propriété. Introduction au dossier. Développement durable et territoires, Dossier 10, p. 0-11, 2008. DOI: https://doi. org/10.4000/developpementdurable.5153. CAFAGGI, Fabrizio; CARON, David D. Global public goods amidst a plurality of legal orders: A symposium. European Journal of International Law, v. 23, n. 3, p. 643-649, 2012.DOI: https://doi.org/10.1093/ejil/chs049. SHAFFER, Gregory. International Law and Global Public Goods in a Legal Pluralist World. European Journal of International Law, v. 23, n. 3, p. 669-693, 2012. DOI: https://doi.org/10.1093/ejil/chs036 compromissos internacionais, mas expressa uma visão minimalista de cooperação internacional ${ }^{40}$.

A segunda se dá em termos de economia política e representa uma visão maximalista de cooperação ${ }^{41}$. Nessa abordagem, dá-se ênfase às relações de interdependência entre poderes públicos e privados e ao "rôle de convergence" que o sentido de BPG aporta à reflexão sobre os valores ou interesses comuns, elevados a "patrimônio comum" da sociedade internacional.

Essa segunda abordagem carrega um sentido epistêmico amplo, cujas adjetivações variam de paradigma "novo" e "subversivo", a "tecnocrático", "eurocêntrico" 42 , um "catch-all concept", e espécie de versão atenuada do desenvolvimentismo neoliberal ${ }^{43}$. É uma abordagem que define os BPGs política e economicamente, nunca a priori, a fim de mobilizar instituições e jurisdições internacionais ${ }^{44}$.

É justamente com base nessa abordagem maximalista de cooperação internacional que este artigo interpreta a criação do COVAX. Ou seja, como uma forma de solução do mal público global "pandemia de coronavírus".

Nessa linha político-econômica, a Teoria de BPG é considerada um paradigma para se repensar as políticas públicas globais. E justamente por isso, Inge Kaul e os demais colaboradores de Global Public Goods: International Cooperation on the 21st Century (1999), considerada a obra de referência nesta matéria, dirigem-se

${ }^{40}$ GABAS, Jean-Jacques; HUGON, Philippe. Les biens publics mondiaux et la coopération internationale. L'Économie politique, v. 12, n. 4, p. 19-31, 2001. DOI: https://doi.org/10.3917/leco.012.0019

${ }^{41}$ GABAS, Jean-Jacques; HUGON, Philippe. Les biens publics mondiaux et la coopération internationale. L'Économie politique, v. 12, n. 4, p. 19, 2001. GIANNATTASIO, Arthur Roberto Capella; PAPY, Luiza Nogueira; NIGRO, Renan Freire. Bens Públicos Globais e sua proteção jurídica internacional: relocalização epistemológica de um debate à luz de princípios de direito político. Direito, Estado e Sociedade, n. 55, p. 69-112, 2019.

42 GABAS, Jean-Jacques; HUGON, Philippe. Les biens publics mondiaux et la coopération internationale. L'Économie politique, v. 12, n. 4, p. 26, 2001.

${ }^{43}$ CARBONE, Maurizio. Supporting or Resisting Global Public Goods? The Policy Dimension of a Contested Concept. Global Governance, v. 13, n. 2, p.185, 2007

${ }^{44}$ GABAS, Jean-Jacques; HUGON, Philippe. Les biens publics mondiaux et la coopération internationale. L Economie politique, v. 12, n. 4, p. 19, 2001. p. 26. https://doi.org/10.3917/leco.012.0019. BOIDIN, Bruno; HIEZ, David; ROUSSEAU, Sandrine. Biens communs, biens publics mondiaux et propriété. Introduction au dossier. Développement durable et territoires, n. Dossier 10, p. 0-11, 2008. p. 5. https://doi.org/10.4000/developpementdurable.5153. 
repetidas vezes aos "policy makers" globais. As limitações do tradicional sistema de cooperação internacional são expostas em favor de uma ressignificação dos arranjos multilaterais em direção a uma arquitetura de governança global ${ }^{45}$.

Inge KAUL ${ }^{46}$ fala em três tipos de hiato (gaps) identificáveis nos esquemas de provisão de BPG. Um hiato jurisdicional (jurisdictional gap), um participativo (participation gap) e um terceiro de incentivos (incentive gap). $\mathrm{O}$ primeiro, aponta para a distância existente entre os mercados globalizados e os centros decisórios de competência nacional. O segundo denuncia uma falta de legitimidade e representatividade das instâncias decisórias. E o terceiro critica a falta de incentivos e de mecanismos de sanção que incitem a produção de BPGs. Considerados conjuntamente, esses hiatos descrevem a atual situação de déficit institucional que explica a falta de provisão adequada de BPGs e, ao mesmo tempo, justifica a multiplicação de arranjos de governança global. ${ }^{47}$

Nessa linha doutrinária, fala-se da "nécessité d'une gestion commune, à l'échelle mondiale"*8 e da criação de um novo multilateralismo ${ }^{49}$, distinto das conhecidas propostas de pluralismo jurídico, consideradas insuficientes para a provisão de $\mathrm{BPGs}^{50}$. O olhar dos analistas volta-

${ }^{45}$ GABAS, Jean-Jacques; HUGON, Philippe. Les biens publics mondiaux et la coopération internationale. L'Économie politique, v. 12, n. 4, p. 26, 2001. BOIDIN, Bruno; HIEZ, David; ROUSSEAU, Sandrine. Biens communs, biens publics mondiaux et propriété. Introduction au dossier. Développement durable et territoires, Dossier 10, p. 5, 2008 .

46 KAUL, Inge; GRÜNBERG, Isabelle; STERN, Marc A. Global Public Goods: International Cooperation on the 21st Century. New York: Oxford University Press, 1999. KAUL, Inge; CONCEIÇÃO, Pedro; LE GOULVEN, Katell; MENDOZA, Ronald U. Providing Global Public Goods. New York: Oxford University Press (OUP), 2003. p. 390-392.

${ }^{47}$ KAUL, Inge; CONCEIÇÃO, Pedro; LE GOULVEN, Katell; MENDOZA, Ronald U. Providing Global Public Goods. New York: Oxford University Press (OUP), 2003. p. 390-392. BOURGUINAT, Henri. Quand les « biens publics » deviennent « globaux ». Sociétal, n. 39, p. 47-50, 2003. p. 49.

48 BOIDIN, Bruno; HIEZ, David; ROUSSEAU, Sandrine. Biens communs, biens publics mondiaux et propriété. Introduction au dossier. Développement durable et territoires, Dossier 10, p. 5, 2008.

49 GABAS, Jean-Jacques; HUGON, Philippe. Les biens publics mondiaux et la coopération internationale. L'Économie politique, v. 12, n. 4, p. 27-28, 2001. JENKS, Bruce. Les Nations unies et les biens publics mondiaux : contributions historiques et défis à venir. Revue internationale de politique de développement, v. 3, n. 3, p. 1-17, 2012. DOI: https://doi.org/10.4000/poldev.947.

${ }^{50}$ SHAFFER, Gregory. International Law and Global Public Goods in a Legal Pluralist World. European Journal of International Law, v. 23, n. 3, p. 673, 2012. -se para as comunidades impactadas pelos males públicos, consideradas como "camadas" de governança ("a system of multilayered regional and global political governance" ${ }^{51}$ o que leva à noção de bens públicos regionais (BPR), tidos como bens intermediários para se alcançar BPG finais ${ }^{52}$

Esse (novo) arranjo de governança global é marcado pela sobreposição geográfica de espaços globais ${ }^{53}$ e pela (intensa) participação de atores não-estatais (públicos e particulares) na produção de instrumentos normativos (jurídicos e não jurídicos), que visam a produção de BPGs, e em última instância, a proteção de valores comuns da sociedade internacional ${ }^{54}$.

Feitas as considerações mais gerais sobre o significado e as implicações do conceito de BPG, retorna-se ao tema central deste artigo, a saber, a produção de vacinas contra o COVID-19 na qualidade de BPGs. Porém, para se avaliar o caso específico das vacinas contra o coronavírus, é preciso, primeiramente, refletir sobre o bem genérico "vacina", para, então, interpretá-lo com base nas diferentes tipologias de BPG.

A partir da perspectiva político-econômica de BPGs, se reconhece que vacinas (em geral) atendem a

51 HELD, David; MCGREW, Anthony. Political Globalization: Trends and Choices. In: KAUL, Inge; CONCEICAO, Pedro; LE GOULVEN, Katell; MENDOZA, Ronald U. Providing Global Goods. New York: Oxford University Press (OUP), 2003. p. 186-187

52 KAUL, Inge; CONCEICAO, Pedro; LE GOULVEN, Katell; MENDOZA, Ronald U. Providing Global Goods. New York: Oxford University Press (OUP), 2003. p.103-104; p.107; p. 142.

53 HELD, David; MCGREW, Anthony. Political Globalization: Trends and Choices, p. 186-187 in KAUL, Inge; CONCEICAO, Pedro; LE GOULVEN, Katell; MENDOZA, Ronald U. Providing Global Goods. New York: Oxford University Press (OUP), 2003. BOURGUINAT, Henri. Quand les « biens publics » deviennent " globaux ». Sociétal, n. 39, p. 47-50, 2003. ESLAVA, Luis. Local space, global life: The everyday operation of international law and development. Local Space, Global Life: The Everyday Operation of International Law and Development. [S. 1.]: Cambridge University Press (CUP), 2015. p. 238. FREUD, Claude. Les biens publics mondiaux. Cabiers d'études africaines, v. 50, n. 198-199-200, p. 1067-1077, 2010. DOI: https://doi.org/10.4000/etudesafricaines.16481. GIANNATTASIO, Arthur Roberto Capella; PAPY, Luiza Nogueira; NIGRO, Renan Freire. Bens Públicos Globais e sua proteção jurídica internacional: relocalização epistemológica de um debate à luz de princípios de direito político. Direito, Estado e Sociedade, n. 55, p.70, 2019.

${ }^{54}$ GOLDMANN, Matthias. A matter of perspective: Global governance and the distinction between public and private authority (and not law). Global Constitutionalism, v. 5, n. 1, p. 48-84, 2016. DOI: https://doi.org/10.1017/s2045381715000209. WEISS, Thomas G.; WILKINSON, RORDEN (ed.). International Organization and Global Governance. 2nd ed. Routledge, 2018. Part IV. 
um interesse público (no âmbito nacional) que possui um correspondente no âmbito internacional, a saúde universal. Portanto, pode-se pensar na proteção deste valor ou patrimônio comum em termos de um BPG, a Saúde Global. Isto não significa que qualquer vacina é ou participa do BPG Saúde Global. Pelo contrário. Significa que, dentro da complexa malha de arranjos de governança global que promovem o BPG Saúde Global, há de se considerar, também, os atores (os não estatais, inclusive) e instrumentos regulatórios (os não jurídicos, inclusive) relativos à produção e distribuição de vacinas. Assim, pode-se considerar que protocolos e normas sanitárias internacionais produzidos por organizações internacionais (OIs), como a OMS ou a Organização Panamericana de Saúde (OPAS), por exemplo, bem como acordos de transferência de tecnologia ${ }^{55}$, de livre-comércio e mesmo Acordos de Compromisso de Compra (Advance Purchase Agreements - APAs) celebrados entre países e indústrias farmacêuticas, tudo isto orbita em torno do BPG Saúde Global ${ }^{56}$.

Nessa dimensão de Governança Global em Saú$\mathrm{de}^{57}$, a provisão normalmente privada do bem vacina pode ser "publicizada" mediante a criação de arranjo de governança que seja capaz de corrigir a rivalidade e exclusividade que lhe são características. Isto foi o que ocorreu no caso do coquetel retroviral, que trata o vírus da AIDS, e no caso da vacina pneumococcal conjugate vaccine (PCV), cujo arranjo de governança inspirou, inclusive, o COVAX, como se verá adiante. Esses tratamentos e

\footnotetext{
55 Para maiores informações sobre a relação entre o conceito de BPG e mecanismos de transferências de tecnologia, vide: MASKUS, Keith E.; REICHMAN, Jerome H. International Public Goods and Transfer of Technology under a Globalized Intellectual Property Regime. Cambridge: Cambridge University Press (CUP), 2005.

56 KLUG, Heinz. Comment: Access to essential medicines. In: MASKUS, Keith E.; REICHMAN, Jerome H. International Public Goods and Transfer of Technology under a Globalized Intellectual Property Regime. Cambridge: Cambridge University Press (CUP), 2005. HARMAN, Sophie. Global Health Governance. In: WEISS, Thomas G.; WILKINSON, Rorden. International Organization and Global Governance. New York: Routledge, 2014. PHELAN, Alexandra L.; ECCLESTON-TURNER, Mark; ROURKE, Michelle; MALECHE, Allan; WANG, Chenguang. Legal agreements: barriers and enablers to global equitable COVID-19 vaccine access. The Lancet, v. 396, n. 10254, p. 800-802, 2020. DOI: https://doi.org/10.1016/S01406736(20)31873-0

${ }^{57}$ KLUG, Heinz. Comment: Access to essential medicines. In MASKUS, Keith E.; REICHMAN, Jerome H. International Public Goods and Transfer of Technology under a Globalized Intellectual Property Regime. Cambridge: Cambridge University Press (CUP), 2005. HARMAN, Sophie. Global Health Governance. In WEISS, Thomas G.; WILKINSON, Rorden. International Organization and Global Governance. New York: Routledge, 2014.
}

vacinas eram providos em quantidade aquém da necessária, pois os atores envolvidos não possuíam condições (países de baixa renda, sem infraestrutura de produção ou recursos para aquisição) ou incentivos (não era considerado rentável para as indústrias farmacêuticas produzirem esses produtos) para provê-los.

Resta apresentar as principais tipologias de bens públicos, e as possíveis interpretações do bem "vacina" que delas se infere.

A primeira classificação se dá em relação à natureza constitutiva dos bens públicos. Ela se divide entre bens públicos puros e bens públicos impuros, e estes últimos podem ser classificados em 'bens de clube' e 'bens de recursos de fundo comum ${ }^{58}$. Aplicando-se essa taxonomia às vacinas, conclui-se que estas não podem ser consideradas bens públicos puros (que são não rivais e também não exclusivos), mas podem ser consideradas bens públicos impuros, dentro de uma lógica de políticas públicas (regionais ou globais) de controle de doenças. Isso, pois é possível remediar as dimensões de rivalidade e exclusividade por meio de arranjos de governança.

Assim, pode-se entender vacinas em um contexto de governança regional como "bens de clube" (club goods), em que o "clube" corresponde à região sujeita a tal governança. De modo que as vacinas distribuídas como parte de campanhas de vacinação, promovidas por organizações internacionais como a OPAS, por exemplo, seriam bens não rivais, mas exclusivos para os integrantes do "clube".

Outras maneiras de se classificar os BPGs dizem respeito a sua posição na cadeia de produção, se bens públicos intermediários ou bens públicos finais, e aos desafios políticos que impõem. Ou seja, se são bens "comuns globais naturais", "comuns globais de criação humana" ou "comuns resultados de políticas globais" 59 .

Finalmente, há a classificação em termos de tecnologias de produção (ou formas de suprimento), que se divide em: bens de "melhor tentativa" (best shot or single best efforts goods), bens de "elo mais fraco" (weakest-link goods)

\footnotetext{
${ }^{58}$ KAUL, Inge; GRÜNBERG, Isabelle; STERN, Marc A. Global Public Goods: International Cooperation on the 21st Century. New York: Oxford University Press, 1999.

${ }^{9}$ KAUL, Inge; GRÜNBERG, Isabelle; STERN, Marc A. Global Public Goods: International Cooperation on the 21st Century. New York: Oxford University Press, 1999.
} 
e bens de "esforços agregados" (aggregate efforts goods) ${ }^{60}$. Essa classificação é especialmente relevante para se pensar as estruturas institucionais mais apropriadas para a produção de determinado bem.

Logo, uma campanha de vacinação universal pela erradicação de certa doença pode ser pensada enquanto um weakest-link good, tendo em vista que a falta de cooperação de um ator (um país que não venha a aderir à campanha, por exemplo), põe em xeque toda a escala de produção do referido bem. Semelhantemente, iniciativas de controle de doenças infecciosas podem ser consideradas bens do tipo esforços agregados, posto que elas requerem um alto grau de cooperação e, consequentemente, estruturas institucionais capazes de promover coordenação política, econômica, informacional etc. ${ }^{61}$.

Desse modo, percebe-se que a provisão das vacinas pode ser problematizada em termos de BPG, e isso sem extrapolar os atuais contornos do conceito. Nesse sentido argumenta Phillipe Hugon:

le concept de bien public mondial est mobilisé par les décideurs publics, par les organisations internationales et par les acteurs de la société civile pour réduire le coût des maux publics, penser et construire une nouvelle architecture internationale fondée sur des coalitions « vertueuses » et un minimum de consensus permettant de dépasser la myopie des marchés et les affrontements inter-étatiques. ${ }^{62}$

\footnotetext{
${ }^{60}$ KAUL, Inge; GRÜNBERG, Isabelle; STERN, Marc A. Global Public Goods: International Cooperation on the 21st Century. New York: Oxford University Press, 1999. GABAS, Jean-Jacques; HUGON, Philippe. Les biens publics mondiaux et la coopération internationale. L'Économie politique, v. 12, n. 4, p. 30, 2001. BARRET, Scott. Why Cooperate? The Incentive to Supply Global Public Goods. [S. 1.]: Oxford University Press, 2007. DOI: https://doi.org/10.11126/ stanford/9780804781329.003.0004. CARBONE, Maurizio. Supporting or Resisting Global Public Goods? The Policy Dimension of a Contested Concept. Global Governance, v. 13, n. 2, p. 182, 2007. SHAFFER, Gregory. International Law and Global Public Goods in a Legal Pluralist World. European Journal of International Law, v. 23, n. 3, p. 679-681, 2012.

${ }^{61}$ SANDLER, Todd in KAUL, Inge; GRÜNBERG, Isabelle; STERN, Marc A. Global Public Goods: International Cooperation on the 21st Century. New York: Oxford University Press, 1999. HUGON, Philippe. Les biens publics mondiaux : un renouveau théorique pour penser l'action publique à l'échelle mondiale ? Politiques et management public, v. 21, n. 3, p. 55-72, 2003. DOI: https://doi. org/10.3406/pomap.2003.2811. SHAFFER, Gregory. International Law and Global Public Goods in a Legal Pluralist World. European Journal of International Law, v. 23, n. 3, p. 679-681, 2012

${ }^{62}$ HUGON, Philippe. Les biens publics mondiaux : un renouveau théorique pour penser l'action publique à l'échelle mondiale ? Politiques et management public, v. 21, n. 3, p. 55-72, 2003. https://doi. org/10.3406/pomap.2003.2811.
}

E, considerando-se que a Teoria de BPGs, e, especialmente, a abordagem político-econômica de BPG constituem relevante instrumental teórico para se buscar a solução do problema de provisão de vacinas contra o coronavírus em termos de arranjos institucionais e esquemas de governança global, propõe-se uma análise do consórcio COVAX à luz da teoria dos BPGs. 4 COVAX: uma análise à luz dos BPGs

\subsection{Estrutura do COVAX}

O COVAX (Covid-19 Vaccine Access) é uma iniciativa interinstitucional estabelecida entre a Organização Mundial de Saúde (OMS), a GAVI - The Vaccine Alliance (GAVI), e a Coalition for Epidemic Preparedness Innovations (CEPI), com parceria de fundos de investimento (como o Fundo Monetário internacional (FMI)), associações filantrópicas (como a Bill\&Mellinda Gates Foundation), e o Fundo das Nações Unidas para a Infância (UNICEF) ${ }^{63}$, que tem por meta: promover o aceleramento do fim da fase aguda da pandemia de COVID-19 e fornecer de 2 (dois) bilhões de vacinas aos grupos populacionais vulneráveis dos países que não têm recursos para adquirir vacinas.

Trata-se do consórcio encarregado do desenvolvimento e fabricação da vacina contra o coronavírus, um dos quatro pilares da força-tarefa Access to Covid Tool (ACT)-Accelerator, iniciada em abril 2020, fruto de um compromisso firmado em março do mesmo ano pelos chefes de Estado integrantes do G20, no sentido de colaborarem pelo fim da pandemia de COVID-19. Além do pilar da Vacina, a força-tarefa ACT - Accelerator investe em Tratamentos Terapêuticos (Therapeutics), Conectores de Sistemas de Saúde (Health System Connectors) e Diagnósticos (Diagnostics), com ênfase em Acesso e Alocação (Access \& Allocation) de todas estas ferramentas. ${ }^{64}$

Para tanto, o COVAX organiza-se em duas frentes: o COVAX Facility ${ }^{65}$ e o COVAX Advance Market Com-

\footnotetext{
${ }^{63}$ Para mias informações sobre a colaboração da UNICEF no mecanismo COVAX, ver: https://www.unicef.org/supply/covaxensuring-global-equitable-access-covid-19-vaccines Acesso em: setembro 2021.

${ }^{64}$ WHO. ACT-Accelerator: Status Report \& Plan7. Switzerland, September 2020 - December 2021. p. 7-8. Disponível em: https:// www.who.int/initiatives/act-accelerator/covax. Acesso em: maio 2021. Acesso em: 24 set. 2021.

65 Para mais informações sobre o consórcio doCOVAX Facility, vide: https://www.gavi.org/vaccineswork/covax-facility-governance-explained. Acesso em: set. 2021.
} 
mitment (AMC). Por meio do COVAX Facility, foram firmadas parcerias com os principais laboratórios de pesquisa e indústrias farmacêuticas empenhadas no desenvolvimento de vacina contra o COVID-19, a fim de formar um portfólio de "candidatas a vacinas" ${ }^{\circ}$. Esse portfólio é apresentado a países e blocos econômicos que pretendem adquirir vacinas para imunizar seus cidadãos. O COVAX AMC, por sua vez, consiste em uma adaptação de um mecanismo desenvolvido e utilizado pela GAVI para aliviar as barreiras de acesso ao mercado de vacinas de uso corrente (como aquelas contra a cólera e o papilomavírus, por exemplo), por parte dos países de baixo poder aquisitivo.

O arranjo do COVAX compreende, portanto, a atuação simultânea das duas frentes, à medida que a primeira, o COVAX Facility, serve para gerar recursos (mediante captação de recursos, doações e os prêmios de entrada dos países aderentes) e a segunda, a COVAX $\mathrm{AMC}$, assegura o acesso à vacina aos países que estariam fora do mercado.

Espera-se dos países aderentes ao COVAX Facility que apresentem o cálculo da quantidade de pessoas que desejam vacinar preferencialmente (entre 5\% e 50\% de suas respectivas populações) e que optem por uma dentre as duas opções de compra de vacinas que oferecidas ${ }^{67}$. Uma, a Optional Purchase Arrangement (Acordo de Compra Opcional), permite que os aderentes adquiram uma cota-parte das vacinas mediante o pagamento de um prêmio de acesso de US $\$ 3,10$ por dose e um valor de garantia compartilhada de US $\$ 00,40$. Como essa opção permite que o aderente se recuse a receber certa vacina, sem prejuízo de receber o total da sua cota-parte, ela é atraente aos países que já realizaram acordos bilaterais de aquisição de vacinas junto a laboratórios específicos.

A outra opção de compra, a Committed Purchase Arrangement (Acordo de Compromisso), possui um prêmio de acesso mais baixo (US\$1,60), e em contrapartida requer uma garantia empenhada e o compromisso de

${ }^{66}$ Este é o termo usado para se referir às vacinas em fase de desenvolvimento cuja a eficácia e segurança ainda não foram atestadas. Atualmente, ao menos duas vacinas já foram aprovadas por certificadoras internacionais, passando de "candidatas" a "vacinas" propriamente ditas.

${ }^{67}$ GAVI. Vaccine Allocation. Fair allocation mechanism for COVID-19 vaccines through the COVAX Facility. Disponível em: https://www.gavi.org/sites/default/files/covid/covax/who-covid19vaccine-allocation-final-working-version-9sept.pdf. Acesso em: 24 set. 2021. efetivamente comprar as vacinas uma vez que estiverem disponíveis. Desse modo, cada país ${ }^{68}$ adquire uma cota-parte das vacinas em desenvolvimento proporcional às suas necessidades, de maneira a reduzir disparidades no acesso à mesma ${ }^{69}$.

Essa forma de aquisição de vacinas, centralizada no COVAX Facility, oferece aos países adquirentes a dupla vantagem de diversificarem suas aquisições mediante o acesso ao portfólio (ao invés de negociarem acordos bilaterais junto a cada laboratório) e de mitigarem os ris$\cos$ (relacionados às vacinas que venham a fracassar) ${ }^{70}$. No caso do Brasil, a Medida Provisória n. 1.003 de 24 de setembro 2020 foi convertida no Projeto de Lei de Conversão (PLV) 43/202, que autoriza o Poder Executivo federal a aderir ao Instrumento de Acesso Global de Vacinas Covid-19 - Covax Facility, e deverá ser apreciada pelo Senado Federal até março de 2021.

Quanto ao COVAX $\mathrm{AMC}^{71}$, este conta com a colaboração de 92 países $^{72}$ de renda baixa e média. Por meio deste mecanismo de colaboração financeira inspirado no Advance Market Commitment for pneumococcal vaccine, desenvolvido pela GAVI Alliance, o COVAX pretende distribuir dois bilhões de vacinas aos profissionais da área da saúde e grupos de risco desses países.

${ }^{68}$ Nos documentos informativos consultados empregou-se o termo "economias" (economies) para fazer abranger aqueles integrantes do COVAX que não são considerados Estados e tampouco são membros da ONU. Vale notar que esse aparente detalhe semântico revela a maleabilidade com que o arranjo do COVAX foi construído. ${ }^{69}$ Em termos de disparidade no acesso à vacina, chama a atenção o caso do Canada, que até dezembro 2020 havia adquirido vacinas em quantidade equivalente a nove doses por cidadão. KOOP, Avery. Tracking COVID-19 Vaccines Around the World. 18 dez. 2020. Disponível em: https://www.visualcapitalist.com/tracking-covid19-vaccines-around-the-world/. Acesso em: 23 set. 2021. LJUNGGREN, D.; MARTELL, A.; NEHEBAY, S. Exclusive: Canada in talks to donate extra COVID-19 vaccine shots to poorer countries - sources. Reuters, Ottawa, Geneva, 18 nov. 2020. Disponível em: https://www.reuters.com/article/us-health-coronavirus-vaccinescovax-exc-idUSKBN27Y2UU . Acesso em: 23 set. 2021.

${ }^{70}$ Quando um país encomenda uma candidata a vacina diretamente do laboratório, via acordo bilateral, e ela acaba por não ser aprovada ou é avaliada como não eficaz, o comprador fica prejudicado.

${ }^{71}$ Mais informações disponíveis, cf. BERKLEY, Seth. The Gavi COVAX AMC Explained. GAVI Vaccine Allocation. Disponível em: https://www.gavi.org/vaccineswork/gavi-covax-amc-explained. Acesso em: 31 maio 2021.

${ }^{72}$ Os países participantes do COVAX - AMC devem seguir o trâmite do COVAX-AMC Application Guidance. Cf. GAVI Vaccine Allocation. COVAX AMC - Application Guidance. 2020. Disponível em: https://www.gavi.org/sites/default/files/covid/covax/covaxamc/COVAX-AMC-APPLICATION-GUIDANCE.pdf. Acesso em: 31 maio 2021. 
Em resumo, o COVAX é um mecanismo de alocação equitativa de vacinas contra o COVID-19, organizado pela GAVI Alliance (os acordos são firmados em seu nome), em conjunto com o CEPI e a OMS. Sua operação se dá por meio de dois instrumentos: o consórcio COVAX Facility, que permite o acesso pelos países a um amplo portfólio de vacinas, e o COVAX Advance Market Commitment, que almeja entregar vacinas a países que não possuem condições financeiras de comprá-los.

\subsection{Impacto do COVAX}

Essa seção não pretende avaliar o impacto do COVAX em termos de êxito da iniciativa ou dos frutos de seu arranjo. Ao contrário, se reconhece que, dada a novidade e atualidade do assunto, é impossível realizar qualquer avaliação empírica do COVAX, por hora. Neste artigo, propõe-se uma reflexão sobre o impacto que o COVAX representa para a Teoria de BPG, e, mais especificamente, para a premissa de que problemas globais (males públicos globais) requerem arranjos de governança global (bens públicos globais) para solucioná-los.

Para isso, serão apresentadas quatro críticas dirigidas ao COVAX e as possíveis objeções que se lhes pode fazer, com base na Teoria de BPG. Estas críticas foram extraídas do comunicado emitido pela organização não governamental Médecins Sans Frontières, em junho de $2020^{73}$.

1) O COVAX representa uma extrapolação das atribuições da GAVI. Esta crítica aponta para o fato de que as atribuições institucionais da GAVI se limitam a projetos de facilitação de acesso a vacinas para um grupo determinado de 58 países elegíveis a um programa de assistência dirigido pela OMS e UNICEF. Embora reconheça que a GAVI possui expertise em provisão de vacinas, a crítica enfatiza que isto não significa que a organização esteja apta a negociar com países de renda média e alta.

Pela ótica dos BPGs, as externalidades de um bem público têm o maior alcance sócio-político possível. De maneira que a alegação de uma extrapolação de atri-

\footnotetext{
73 MSF. COVID-19 Vaccine Global Access (COVAX) Facility: Key considerations for Gavi's new global financing mechanism. MSF Briefing Document, June 2020, p.1-9. Disponível em: https://msfaccess. org/sites/default/files/2020-06/MSF-AC_COVID-19_Gavi-COVAXFacility_briefing-document.pdf. Acesso em: 22 set. 2021.
}

buições institucionais não constituiria um óbice em si mesma, seria até mesmo uma consequência esperada ${ }^{74}$. O que importa, nessa pragmática perspectiva, é buscar arranjos capazes de prover os BPGs almejados com a maior eficiência possível. Evidentemente, limitações legais devem ser observadas, mas este não seria um caso de afronta à autoridade moral da instituição ${ }^{75}$, visto que essas novas atribuições (do COVAX) são condizentes com as suas atribuições originárias. $\mathrm{Na}$ interpretação de KLUG, "this failure in global governance leaves each negotiating or interest community to rely upon its own expertise and assumptions about subject matter and priority to define the parameters of its debate and feasible outcomes." 76

2) Não houve avaliação prévia para determinar se a criação de um esquema global era realmente necessária.

The need for a new global superstructure to procure future COVID-19 vaccines has not been established, and no analysis has been made available on the needs, advantages or disadvantages of such a global mechanism. [...]Supporting regional groups and coordinating between them to ensure no country is left out may be a more expedient approach. This would not require creating new global organisational infrastructure, nor risk costly and time-consuming duplication of already existing mechanisms. ${ }^{77}$

O argumento da urgência, amparado no da eficiência, justifica, nesse ponto, a falta de estudo preliminar. Os potenciais benefícios do BPG seriam reduzidos à medida que sua implementação, se demorasse. A celeridade no processo de implementação do esquema produtor do BPG justificaria, portanto, a atuação dos policy makers. $^{78}$

\footnotetext{
74 SHAFFER, Gregory. International Law and Global Public Goods in a Legal Pluralist World. European Journal of International Law, v. 23, n. 3, p. 670, 2012.

${ }^{75}$ CARBONE, Maurizio. Supporting or Resisting Global Public Goods? The Policy Dimension of a Contested Concept. Global Governance, v. 13, n. 2, p. 179-198, 2007.

${ }^{76}$ KLUG, Heinz. Comment: Access to essential medicines. In: MASKUS, Keith E.; REICHMAN, Jerome H. International Public Goods and Transfer of Technology under a Globalized Intellectual Property Regime. Cambridge: Cambridge University Press (CUP), 2005. p. 483. 77 MSF. COVID-19 Vaccine Global Access (COVAX) Facility: Key considerations for Gavi's new global financing mechanism. MSF Briefing Document, June 2020, p.1-9. Disponível em: https://msfaccess. org/sites/default/files/2020-06/MSF-AC_COVID-19_Gavi-COVAXFacility_briefing-document.pdf. Acesso em: 22 set. 2021.

78 BARRET, Scott. Why Cooperate? The Incentive to Supply Global Public Goods. [S. 1.]: Oxford University Press, 2007. p. 19.
} 
3) $\mathrm{O}$ Advance market commitment for pneumococcal conjugate vaccine (PCV), que inspirou o COVAX AMC, foi utilizado em circunstâncias muito distintas das atuais.

O fato de que aquele programa teve duração de 5 anos (2005-2010), visava, somente, países beneficiários do GAVI AMC e, segundo auditores independentes, teria sido, apenas, parcialmente exitoso pode depor contra o COVAX. No entanto, considerando, novamente, a urgência do caso, é compreensível que os policy makers lançassem mão de instrumentos utilizados no passado, ainda que não sejam os instrumentos mais recomendáveis. Claude FREUD assim expõe as prioridades da abordagem de BPG:

la théorie des « biens publics mondiaux » s'intéressera alors à l'injustice que constitue l'inégalité de l'accès à l'information au regard des conditions de fonctionnement du marché, cherchera les imperfections et dysfonctionnements les permettant ou les produisant, et proposera des remèdes aux problèmes qui en sont la source. $^{79}$

4) COVAX apenas negocia preço da vacina, não buscou providenciá-las enquanto bens públicos globais, a preço de custo

Civil society has criticised COVAX for negotiating prices that include profit rather than vaccines at cost as a global public good, the lack of transparency of contracts entered into with vaccine manufacturers, limits on civil society participation, failure to address potential impacts of intellectual property rights on pandemic vaccines, and governance questions, including the role of WHO and limited experience procuring vaccines for middle-income countries and HICs. ${ }^{80}$

Considerando-se que o conceito de BPG é interdisciplinar e plurívoco ${ }^{81}$, é possível argumentar que a MSF pontuou esta sua crítica com base em apenas uma interpretação do que sejam BPGs. Como visto neste artigo,

\footnotetext{
79 FREUD, Claude. Les biens publics mondiaux. Cabiers d'études africaines, v. 50, n. 198-199-200, p. 1067-1077, 2010. DOI: https://doi. org/10.4000/etudesafricaines.16481.

80 PHELAN, Alexandra L.; ECCLESTON-TURNER, Mark; ROURKE, Michelle; MALECHE, Allan; WANG, Chenguang. Legal agreements: barriers and enablers to global equitable COVID-19 vaccine access. The Lancet, v. 396, n. 10254, p. 801, 2020.

${ }^{81}$ GIANNATTASIO, Arthur Roberto Capella; PAPY, Luiza Nogueira; NIGRO, Renan Freire. Bens Públicos Globais e sua proteção jurídica internacional: relocalização epistemológica de um debate à luz de princípios de direito político. Direito, Estado e Sociedade, n. 55 , p. $28-29,2019$.
}

é possível abordar o problema da provisão de vacina contra COVID-19 enquanto um BPG, independentemente do preço do produto final (bem de consumo) vacina. Conforme ressalta Inge KAUL: "publicness and privateness are in most cases not innate properties of a good but social constructs, a policy choice". ${ }^{82}$

\section{Cosiderações finais}

Se a globalização, entendida como estreitamento do mundo, como trocas e fluxos intensificados, como uma passagem das relações do nacional para o transnacional, como a unificação da humanidade num destino comum, demandasse uma prova, a pandemia do Covid-19 poderia bem servir. Num certo sentido, uma pandemia, especialmente quando tão impactante para os sistemas de saúde nacionais e tão dependente de respostas coletivas como essa, é a melhor ilustração da conexão entre todos, no mundo inteiro.

Essa conexão evidente pode ser pensada como a consequência, "natural" ou "espontânea" 83 de processos de avanço tecnológico, aceleração dos tempos e facilidade de comunicação e transporte.

Mas a globalização pode ser pensada também como algo "construído", criado em certa medida, de modo "intencional", pensado. O Direito, na medida em que incide sobre o transnacional ou o internacional, pode participar dessa construção da globalização ou pode participar da construção de respostas comuns a questões postas pela globalização. Nesse sentido, globaliza-se a resposta jurídica à globalização das trocas.

Assim, também é com o que pode ser referido como Governança. Mas, como dito antes, a Governança parece pretender a construção de um coletivo que vai além dos Estados e de seu Direito.

A problematização das vacinas contra o coronavírus em termos de BPG mostrou-se um raciocínio viável.

\footnotetext{
${ }^{82}$ KAUL, Inge in PETERSMANN, Ernst-Ulrich. Multilevel governance of Interdependent public goods theories, rules and institutions for the central policy challenges in the 21st Century. Global Governance, v. RSCAS 2010, n. 2, p. 30, 2010. DOI 10.2139/ssrn.2481918. Available at: http://cadmus.eui.eu/handle/1814/13218.

83 NASSER, Salem Hikmat; GHIRARDI, José Garcez. LAW AND GLOBALIZATION: A CRITIQUE OF A DIALECTIC RELATION. Revista da Faculdade de Direito da UFMG, n. 77, p. 339-357, jul./dez. 2020. DOI: 10.12818/P.0304-2340.2020v77p339.
} 
Mais do que isso, encontrou-se, na literatura de Bens Públicos Globais, um instrumental teórico para se avaliar arranjos de governança global. $\mathrm{O}$ arranjo selecionado nesta pesquisa foi o COVAX, que ainda se encontra em fase de desenvolvimento e implementação, dada a urgência e a atipicidade das circunstâncias em que ele se insere.

No entanto, o que essa análise do COVAX revelou não foi uma iniciativa salvífica de governança global, mas um arranjo de governança com aspiração global, reduzido a mais um fórum de cooperação multilateral.

Assim, aquilo que fazia a prova da globalização aparece agora como revelador de formas muito particulares pelas quais se realiza o recolhimento dos atores sociais a seus próprios interesses (tal como erroneamente percebidos) e dos golpes com que passam a castigar as respostas coletivas aos problemas coletivos.

Ao desafio da pandemia, aos riscos contra um Bem Público Global indiscutível que é a saúde, a resposta da Governança e de seus mecanismos, assim como a resposta do Direito Internacional, falhou em produzir a resposta coletiva necessária, e única com esperanças de eficácia, que garantiria o Bem Público Global vacina.

\section{Referências}

ARHIN-TENKORANG, Dyna; CONCEIÇÃO, Pedro. Beyond Communicable Disease Control: Health in the Age of Globalization. In. KAUL, Inge; CONCEICAO, Pedro; LE GOULVEN, Katell; MENDOZA, Ronald U. Providing Global Goods. New York: Oxford University Press (OUP), 2003. DOI: 10.1093/0195157400.001.0001

BARRET, Scott. Creating Incentives for Cooperation: Strategic Choices. In KAUL, Inge; CONCEIÇÃO, Pedro; LE GOULVEN, Katell; MENDOZA, Ronald U. Providing Global Public Goods. [S. 1.: s. n.], 2013. v. 01.

BARRET, Scott. Why Cooperate? The Incentive to Supply Global Public Goods. Oxford: Oxford University Press, 2007.

BERKLEY, Seth. The Gavi COVAX AMC Explained. GAVI Vaccine Allocation. Disponível em: https:// www.gavi.org/vaccineswork/gavi-covax-amc-explained. Acesso em: 31 maio 2021.
BOIDIN, Bruno; HIEZ, David; ROUSSEAU, Sandrine. Biens communs, biens publics mondiaux et propriété. Introduction au dossier. Développement durable et territoires. Dossier 10, p. 0-11, 2008. DOI: https://doi. org/10.4000/developpementdurable.5153

BOLLYKY, Thomas J; BOWN, Chad P; CAMPBELL, Joseph. The Tragedy of Vaccine Nationalism: Only Cooperation Can End the Pandemic. Foreign Affairs. jul. 2020. Disponível em: https://www.foreignaffairs.com/ articles/united-states/2020-07-27/vaccine-nationalism-pandemic. Acesso em: 22 set. 2021

BOURGUINAT, Henri. Quand les «biens publics » deviennent « globaux ». Sociétal, n. 39, p. 47-50, 2003.

CAFAGGI, Fabrizio; CARON, David D. Global public goods amidst a plurality of legal orders: A symposium. European Journal of International Law, v. 23, n. 3, p. 643649, 2012.DOI: https://doi.org/10.1093/ejil/chs049

CAFAGGI, F. New Foundations of Transnational Private Regulation. Journal of Law and Society, v. 38, n. 1, p. 20-49, 2011.

CARBONE, Maurizio. Supporting or Resisting Global Public Goods? The Policy Dimension of a Contested Concept. Global Governance, v. 13, n. 2, p. 179-198, 2007.

CASSESE, S. Global Administrative Law: An Introduction. IIJL Conference. Anais. 2005. p. 1-46.

CHEN, Lincoln C., EVANS, Tim G., CASH, Richard A. Health as a Global Public Good. In: KAUL, Inge; GRÜNBERG, Isabelle; STERN, Marc A. Global Public Goods: International Cooperation on the 21st Century. New York: Oxford University Press, 1999.

ESLAVA, Luis. Local space, global life: The everyday operation of international law and development. Local Space, Global Life: The Everyday Operation of International Law and Development. [S. 1.]: Cambridge University Press (CUP), 2015. DOI: https://doi.org/10.1017/ CBO9781316135792

FIDLER, David P. Vaccine nationalism's politics. Science, v. 369, n. 6505, p. 749, 2020. DOI: https://doi. org/10.1126/science.abe2275

FREUD, Claude. Les biens publics mondiaux. Cabiers d'études africaines, v. 50, n. 198-199-200, p. 1067-1077, 2010. DOI: https://doi.org/10.4000/etudesafricaines.16481 
GABAS, Jean-Jacques; HUGON, Philippe. Les biens publics mondiaux et la coopération internationale. L'Économie politique, v. 12, n. 4, p. 19-31, 2001. DOI: https://doi.org/10.3917/leco.012.0019

GAVI Vaccine Allocation. COVAX AMC - Application Guidance. 2020. Disponível em: https://www. gavi.org/sites/default/files/covid/covax/covax-amc/ COVAX-AMC-APPLICATION-GUIDANCE.pdf. Acesso em: 31 maio 2021.

GAVI. The COVAX Vaccines Pillar of the Access to COVID-19 Tools (Act) Accelerator: structure and principles.9 november 2020 (updated in march 2021). Disponível em: https://www.gavi.org/sites/default/files/covid/ covax/COVAX_the-Vaccines-Pillar-of-the-Access-toCOVID-19-Tools-ACT-Accelerator.pdf. Acesso em: setembro 2021.

GERHART, Peter in MASKUS, Keith E.; REICHMAN, Jerome H. International Public Goods and Transfer of Technology under a Globalized Intellectual Property Regime. Cambridge: Cambridge University Press (CUP), 2005.

GIANNATTASIO, Arthur Roberto Capella; PAPY, Luiza Nogueira; NIGRO, Renan Freire. Bens Públicos Globais e sua proteção jurídica internacional: relocalização epistemológica de um debate à luz de princípios de direito político. Direito, Estado e Sociedade, n. 55, p. 69-112, 2019.

GOLDMANN, Matthias. A matter of perspective: Global governance and the distinction between public and private authority (and not law). Global Constitutionalism, v. 5, n. 1, p. 48-84, 2016. DOI: https://doi.org/10.1017/ s2045381715000209.

GUIMARÃES, Maria João. Israel dá vacinas à República Checa, que vai abrir representação diplomática em Jerusalém. Disponível em: https://www.publico.pt/2021/02/24/ mundo/noticia/israel-vacinas-republica-checa-vaiabrir-representacao-diplomatica-jerusalem-1951935. Acesso em: 31 maio 2021.

HALE, Thomas; HELD, David; YOUNG, Kevin. Gridlock: Why Global Cooperation is Failing When We Need it Most. Cambridge: Polity, 2013.

HARMAN, Sophie. Global Health Governance. In: WEISS, Thomas G.; WILKINSON, Rorden. International Organization and Global Governance. New York: Routledge, 2014.
HUGON, Philippe. Les biens publics mondiaux: un renouveau théorique pour penser l'action publique à l'échelle mondiale? Politiques et management public, v. 21, n. 3, p. 55-72, 2003.

IKENBERRY, G. John. The Next Liberal Order: The Age of Contagion Demands More Internationalism, Not Less. Foreign Affairs, Aug. 2020.

JENKS, Bruce. Les Nations unies et les biens publics mondiaux : contributions historiques et défis à venir. Revue internationale de politique de développement, v. 3, n. 3, p. 1-17, 2012. DOI: https://doi.org/10.4000/poldev.947

KACOWICZ, Arie M. Global Governance, International Order, and World Order. In: LEVI-FAUR, David (ed.). Oxford Handbook of Governance. [S. l.]: Oxford University Press, 2012.

KAUL, Inge; CONCEICAO, Pedro; LE GOULVEN, Katell; MENDOZA, Ronald U. Providing Global Goods. New York: Oxford University Press (OUP), 2003. DOI: $10.1093 / 0195157400.001 .0001$

KAUL, Inge; GRÜNBERG, Isabelle; STERN, Marc A. Global Public Goods: International Cooperation on the 21st Century. New York: Oxford University Press, 1999.

KINDLEBERGER, Charles. International Public Goods without International Government. American Economic Review, v. 76, n. 1, p. 1-13, 1986.

KINGSBURY, B. et al. Foreword: Global Governance as Administration: National and Transnational Approaches to Global Administrative Law. Law and Contemporary Problems, v. 68, n. 3-4, p. 1-13, 2005.

KINGSBURY, B.; KRISCH, N.; STEWART, R. B. The Emergence of Global Administrative Law. Law and Contemporary Problems, v. 68, p. 15-61, 2005.

KLUG, Heinz. Comment: Access to essential medicines. In MASKUS, Keith E.; REICHMAN, Jerome H. International Public Goods and Transfer of Technology under a Globalized Intellectual Property Regime. Cambridge: Cambridge University Press (CUP), 2005.

KOOP, Avery. Tracking COVID-19 Vaccines Around the World. Visual Capitalist, 18 dez. 2020. Disponível em: https://www.visualcapitalist.com/tracking-covid19-vaccines-around-the-world/. Acesso em: 23 set. 2021.

KRISCH, N.; KINGSBURY, B. Introduction: Global Governance and Global Administrative Law in the In- 
ternational Legal Order. European Journal of International Law, v. 17, n. 1, p. 1-13, 2006. DOI: 10.1093/ejil/chi170

LJUNGGREN, D.; MARTELL, A.; NEHEBAY, S. Exclusive: Canada in talks to donate extra COVID-19 vaccine shots to poorer countries - sources. Reuters, Ottawa, Geneva, 18 nov. 2020. Disponível em: https:/ / www.reuters.com/article/us-health-coronavirus-vaccines-covax-exc-idUSKBN27Y2UU . Acesso em: 23 set. 2021.

LONG, David; WOOLLEY, Frances. Global Public Goods: Critique of a UN Discourse. Global Governance, v. 15 , n. 1, p. 107-122, 2009. DOI:

MARLOW, I.; CHAUDHARY, A.; LINDBERG, K. S. India Beats China at Its Own Game in Vaccine Diplomacy Fight. Bloomberg, 25 fev. 2021. Disponível em: https:/ / www.bloomberg.com/news / articles/2021-02-25/india-beats-china-at-its-own-game-in-vaccine-diplomacybattle. Acesso em: 31 maio 2021.

MINISTERE DES AFFAIRES ÉTRANGERES. Les biens publics mondiaux. [S. 1.]: Ministère des Affaires étrangères, févr. 2002. Disponível em: https://www.diplomatie.gouv.fr/IMG/pdf/Les_biens_publics_mondiaux-2.pdf. Acesso em: 22 set. 2021

MSF. COVID-19 Vaccine Global Access (COVAX) Facility: Key considerations for Gavi's new global financing mechanism. MSF Briefing Document, June 2020. Disponível em: https://msfaccess.org/sites/default/ files/2020-06/MSF-AC_COVID-19_Gavi-COVAXFacility_briefing-document.pdf. Acesso em: 22 set. 2021.

NASSER, Salem Hikmat; GHIRARDI, José Garcez. Around the pyramid: Political-theoretical challenges to law in the age of global governance. Revista de Direito Internacional, v. 15, n. 1, p. 61-69, 2018. DOI: https:// doi.org/10.5102/rdi.v15i1.4934

NASSER, Salem Hikmat. NASSER, Salem Hikmat. GHIRADI, José Garcez. O que se diz e que se cala: a governança entre a fuga do direito e a busca pelo controle. Revista do Programa de Pós-graduação em Direito da UFC, v. 38, n. 2, p. 731-744, jul./dez. 2018. Disponível em: http://www.periodicos.ufc.br/nomos/article/ view/3981. Acesso em: set. 2021.

NASSER, Salem Hikmat. Fontes e Normas do Direito Internacional: Um Estudo sobre a Soft Law. 2a. ed. São Paulo: Editora Atlas, 2006.
NASSER, Salem Hikmat. Direito Global em Pedaços: Fragmentação, Regimes e Pluralismo. Revista de Direito Internacional, v. 12, n. 2, p. 98-126, 2015. DOI: 10.5102/ rdi.v12i2.3707

NASSER, Salem Hikmat; GHIRARDI, José Garcez. LAW AND GLOBALIZATION: A CRITIQUE OF A DIALECTIC RELATION. Revista da Faculdade de Direito da UFMG, n. 77, p. 339-357, jul./dez. 2020. DOI: 10.12818/P.0304-2340.2020v77p339

NORDHAUS, William D. Paul Samuelson and global public goods: A commemorative essay for Paul Samuelson. Samuelsonian economics and the twenty-first century. Oxford: Oxford University Press, 2006.

OLSON, Mancur. The Logic of Collective Action: Public Goods and The Theory of Groups. Cambridge: Harvard University Press, 1965.

OST, François; KERCHOVE, Michel van de. De la pyramide au réseau? Pour une théorie dialectique du droit. Bruxelles: Presses des Facultés Universitaires SaintLouis, 2002.

PETERSMANN, Ernst-Ulrich. Multilevel governance of Interdependent public goods theories, rules and institutions for the central policy challenges in the 21st Century. Global Governance, v. RSCAS 2010, n. 2, p. 30, 2010. DOI: $10.2139 /$ ssrn.2481918. Available at: https:// cadmus.eui.eu/bitstream/handle/1814/22275/ RSCAS_2012_23final.pdf? sequence $=2$ \&isAllowed $=\mathrm{y}$.

PETERSMANN, Ernst-Ulrich. International Economic Law and "Public REason": Why do governments fail to protect International Public Goods more effectively? European University Institute, Florenza, v. 17, n. 1, p. 28-36, 2010.

PHELAN, Alexandra L.; ECCLESTON-TURNER, Mark; ROURKE, Michelle; MALECHE, Allan; WANG, Chenguang. Legal agreements: barriers and enablers to global equitable COVID-19 vaccine access. The Lancet, v. 396, n. 10254 , p. 800-802, 2020.

PRANGE, Astrid. A diplomacia da vacina vai melhorar a imagem da China? DW, 25 fev. 2021. Disponível em: https://p.dw.com/p/3pvWg. Acesso em: 30 maio 2021.

PORTO, Gabriela Hühne; ALMEIDA, Paula Wojcikiewicz; NETTO, Juliana Maria F.A. International Regulation and Global Governance: the EU influential method in times of normativity change. Brazilian Journal of International Law, v. 17, n. 1, p. 373-390, 2020. Di- 
sponível em: https://doi.org/10.5102/rdi.v17i1.6167. Acesso em: set. 2021.

SANCHEZ, M. R. The Global Administrative Law Project: A review from Brazil. Artigos Direito GV. 1 Oct. 2008. Disponível em: https://ssrn.com/abstract $=1483379$. Acesso em: 22 set. 2009. DOI: http:// dx.doi.org/10.2139/ssrn.1483379

SANDLER, Todd in KAUL, Inge; GRÜNBERG, Isabelle; STERN, Marc A. Global Public Goods: International Cooperation on the 21 st Century. New York: Oxford University Press, 1999. DOI:10.1093/0195130529.003.0002

SHAFFER, Gregory. International Law and Global Public Goods in a Legal Pluralist World. European Journal of International Law, v. 23, n. 3, p. 669-693, 2012.

SHAPIRO, Martin. The Globalization of Law. Indiana Journal of Global Legal Studies, v. 1, n. 1, Article 3, 1993. Disponível em: https://www.repository.law.indiana. edu/ijgls/vol1/iss1/3. Acesso em: 22 set. 2021.

VENTURA, Deisy de Freitas Lima; MARTINS, Jameson. Between Science and Populism: the Brazilian response to COVID-19 from the perspective of the legal determinants of Global Health. Revista de Direito Internacional, v. 17, n. p. 67-83, 2, 2020. https://doi. org/10.5102/rdi.v17i2.6687.

VON BOGDANDY, A. General Principles of International Public Authority: Sketching a Research Field. German Law Journal, v. 9, n. 11, p. 1909-1939, 2008. DOI: 10.1017/S2071832200000699

VON BOGDANDY, A., DANN, P., GOLDMANN, M. Developing the Publicness of Public International Law: Towards a Legal Framework for Global Governance Activities. German Law Journal, v. 9, n. 11, p. 13751400, 2008. DOI:10.1017/S2071832200000511

WEISS, Thomas G.; WILKINSON, RORDEN (ed.). International Organization and Global Governance. 2nd ed. Routledge, 2018.

WHO. ACT-Accelerator: Status Report \& Plan. Switzerland, September 2020 - December 2021. Disponível em: https://www.who.int/publications/m/item/actaccelerator-status-report-and-plan. Acesso em: 24 set. 2021.
ZHAOYI, Pan. Chinese vaccines will be made global public good, says Xi. CGNT, 19 maio 2020. Disponível em: https://news.cgtn.com/news/2020-05-19/Chinesevaccines-will-be-made-global-public-good-says-XiQCpFSGIL2g/index.html. Acesso em: 31 maio 2021. 
Para publicar na Revista de Direito Internacional, acesse o endereço eletrônico www.rdi.uniceub.br ou www.brazilianjournal.org.

Observe as normas de publicação, para facilitar e agilizar o trabalho de edição. 